\title{
Comprehensive Review of Thyroid Embryology, Anatomy, Histology, and Physiology for Surgeons
}

\author{
Rodrigo Arrangoiz*, Fernando Cordera, David Caba, Manuel Muñoz, \\ Eduardo Moreno, Enrique Luque de León
}

Department of Surgical Oncology/Head and Neck Division of the American British Cowdray Medical Center, Mexico City, Mexico Email: *rodrigo.arrangoiz@gmail.com

How to cite this paper: Arrangoiz, R., Cordera, F., Caba, D., Muñoz, M., Moreno, E. and de León, E.L. (2018) Comprehensive Review of Thyroid Embryology, Anatomy, Histology, and Physiology for Surgeons. International Journal of Otolaryngology and Head \& Neck Surgery, 7, 160-188. https://doi.org/10.4236/ijohns.2018.74019

Received: May 29, 2018

Accepted: July 13, 2018

Published: July 16, 2018

Copyright $\odot 2018$ by authors and Scientific Research Publishing Inc. This work is licensed under the Creative Commons Attribution International License (CC BY 4.0).

http://creativecommons.org/licenses/by/4.0/

\begin{abstract}
Emil Theodor Kocher and Theodor Billroth pioneered the surgical management of thyroid disease. Their surgical techniques, knowledge of thyroid anatomy, embryology, histology, physiology, and antisepsis practices transitioned a life-threatening operation to one with acceptable morbidity. The modern head and neck surgeon should have a meticulous surgical technique, combined with a thorough understanding of thyroid embryology and anatomy that is central to the understanding and treatment of the different disease processes of the thyroid gland and the consequences of thyroid gland surgery. In this manuscript we will be examining thyroid gland embryology, anatomy, histology, and physiology that is essential to the practicing thyroid surgeon.
\end{abstract}

\section{Keywords}

Thyroid Gland Embryology, Thyroid Gland Anatomy, Thyroid Gland Histology, Thyroid Gland Physiology, Thyroid Gland

\section{Introduction}

The modern head and neck surgeon/endocrine surgeon/thyroid surgeon should have a complete understanding of the basic science behind the development of the thyroid and parathyroid glands as well as knowledge of the possible congenital abnormalities arising out of these glands, as they may impact the completeness of surgery as well as the complications of surgery. The modern thyroid surgeon comes to a more innate understanding of surgical anatomy through the comprehensive grasp of the underlying formative embryology.

The lifetime risk of developing thyroid dysfunction is common [1] [2]. Sub- 
clinical and overt hypothyroidism occurs in $4.6 \%$ to $9.5 \%$ [3] [4], whereas subclinical and overt hyperthyroidism occurs in $1.3 \%$ to $2.2 \%$ of the population [1] [3] [4]. The incidence of thyroid cancer has been increasing steadily since the mid-1990s with an estimated incidence of 53,990 in 2018 [5]. This cancer represents the most common endocrine malignancy and accounts for approximately $3 \%$ of all human malignancies, with $75 \%$ of cases occurring in women [5] [6]. As we can see the prevalence of thyroid disease is high and, in many instances, surgery forms an integral part of the treatment, so a complete understanding of the embryology, anatomy, histology, and physiology is essential to any surgeon that will be managing thyroid diseases.

\section{Thyroid Gland Embryogenesis}

The modern head and neck surgeon should have a complete grasp of the embryogenesis of the thyroid gland as well as knowledge of the possible congenital anomalies arising out of this gland, as they may influence the completeness of the surgery as well as the complications arising from operations of the thyroid gland.

The thyroid gland is the first of the body's endocrine glands to develop, appearing as an outpouching of the primitive foregut around the third week of gestation (roughly the $24^{\text {th }}$ day) [7]. The thyroid gland forms as a proliferation (thickening) of the endodermal epithelial cells found on the median surface of the developing pharyngeal floor [8]. The site of this development lies between two key structures, the tuberculum impar and the copula, and is recognized as the foramen cecum (Figure 1) [9].

The foramen cecum located at the base of the tongue is the site of origin of the thyroid gland at the junction between the first and second branchial (pharyngeal) pouches, immediately dorsal to the aortic sac [8] [10]. The thyroid gland has a double embryologic origin: the primitive pharynx and the neuroectoder$\mathrm{mal} /$ neural crest [9]. The thyroid gland initially arises caudal to the tuberculum
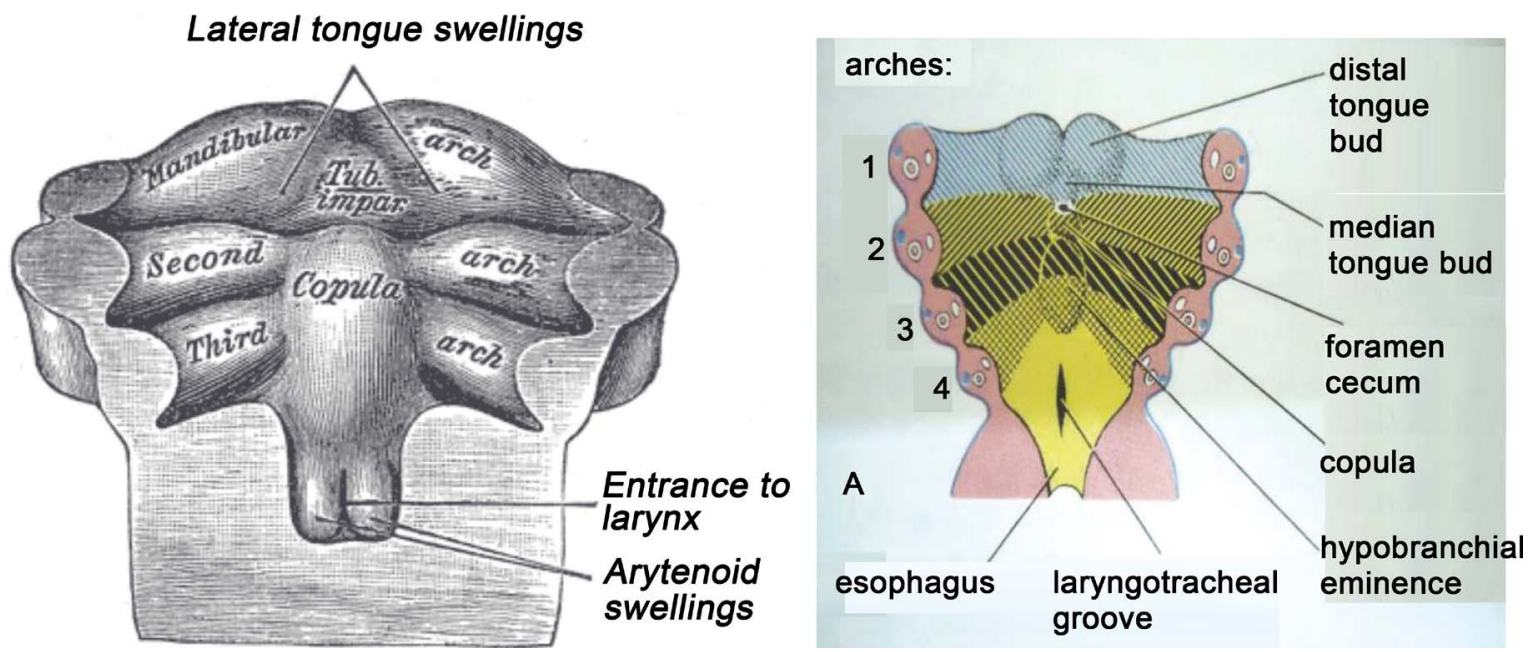

Figure 1. Origin of thyroid gland at the foramen cecum and the tuberculum impar (median tongue bud). 
impar, which is also known as the median tongue bud (Figure 1) [11]. This embryonic swelling develops from the first branchial arch and occurs on the midline of the floor of the developing pharynx, eventually helping form the tongue as the two lateral lingual swellings overgrow it [11]. The foramen cecum begins rostral to the copula, also known as the hypobranchial (hypopharyngeal) eminence (Figure 1). This median embryologic swelling consists of mesoderm that arises from the second branchial pouch (although the third and fourth branchial pouches are also involved). The thyroid gland, therefore, originates between the first and second branchial pouches [10].

The initial thyroid precursor, the thyroid primordium, starts as a simple midline thickening (endoderm) and develops to form the thyroid diverticulum or thyroid anlage (this median anlage forms the bulk of the thyroid gland) [12]. This structure at the outset is initially hollow, though it later solidifies (forming the follicular elements of the thyroid gland) and becomes bilobed. Division of the thyroid gland into lateral lobes, if not present from the beginning, takes place so early that it is impossible to establish whether the thyroid arises as a single unit or as a paired organ. The stalk usually has a lumen, the thyroglossal duct, that does not descend into the lateral lobes [12]. The two lobes are located on either side of the midline and are connected via an isthmus (Figure 2). This thyroid anlage follows the primitive heart as it descends caudally [12]. Early during the fifth week of gestation, the attenuated duct loses its lumen and subsequently breaks into fragments. The proximal part retracts and vanishes, leaving only the foramen cecum at the base of the tongue to mark its origin, and the caudal end develops as the bilobed encapsulated thyroid gland and reaches its final adult position by the $7^{\text {th }}$ week of gestation [9].

The paired lateral anlages originate from the ventral portions of the fourth and fifth branchial pouches and fuse with the median thyroid anlage at approximately the fifth week of gestation [7], contributing up to $30 \%$ of the thyroid gland weight [12]. The lateral anlages are neuroectodermal/neural crest in origin (ultimobranchial bodies) and produce the calcitonin producing parafolicullar or $\mathrm{C}$ cells (from the neural crest these the C-cells migrate to the ultimobranchial bodies), which come to lie in the superior posterior region of the thyroid gland

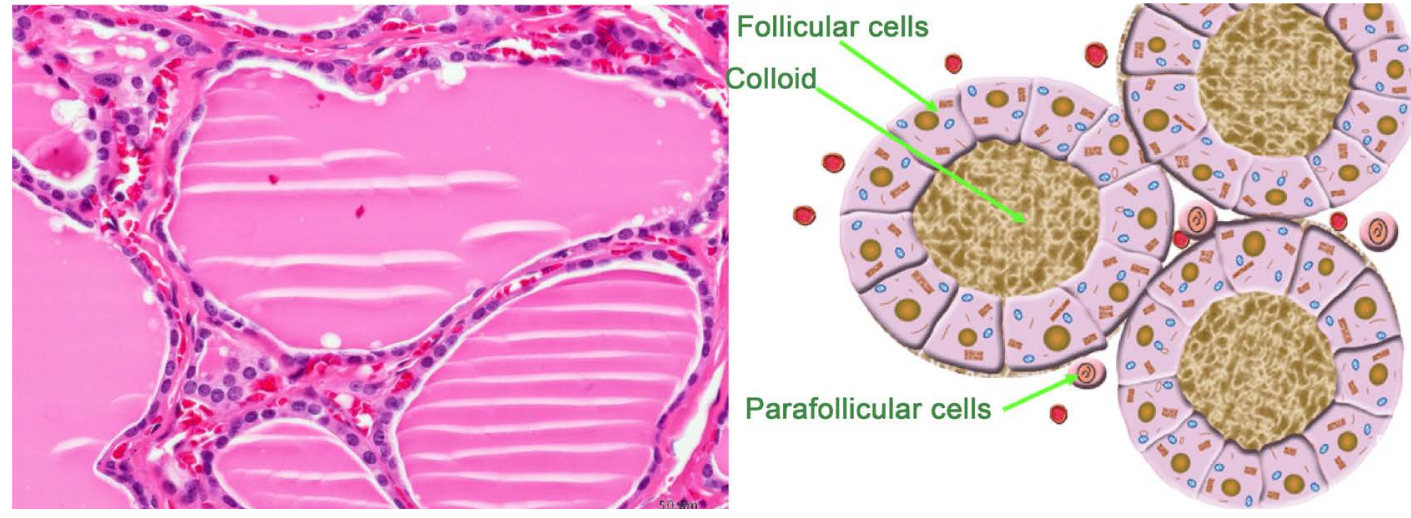

Figure 2. Thyroid Follicles and thyroid parafollicular or C cells. 
[7] [8] [12] [13]. The fusion of the median thyroid anlage and the ultimobranchial bodies explains why the parafollicular cells or $\mathrm{C}$ cells are not scattered throughout the entire thyroid but are limited to a region deep within the middle to upper thirds of the lateral lobes along an imaginary central lobar axis [14]. The bases for the fusion of the median and lateral thyroid anlages is unclear, but the site of the fusion of these two structures is stated to occur at the tubercle of Zuckerkandl [15] [16]. The parafolicullar or $\mathrm{C}$ cells belong to a group of neural-crest derivatives known as the amine precursor uptake and decarboxylation cells (APUD) [17].

The thyroid follicular cells develop from the median thyroid anlage and become apparent around the $8^{\text {th }}$ week of gestation and start producing colloid and take up radioactive iodine around the $11^{\text {th }}$ week of gestation [8] [12]. Evidence of thyroxine comes with the appearance of colloid [8] [12]. The development of the thyroid follicle is heralded by the appearance of an intracellular periodic acid-Schiff (PAS)-positive material, which leads to follicle formation by budding or division of the primary follicles [12]. The histologic differentiation of the thyroid gland can be conceptualized into three stages: pre-colloid (7 to 13 weeks); colloid (13 to 14 weeks); and follicular (after 14 weeks) [12].

\section{Thyroid Gland Histology}

The thyroid gland is enclosed by the thyroid capsule, which is a thin, dense layer of connective tissue that sends septa into the thyroid parenchyma, subdividing the thyroid gland into several lobules [8]. Each thyroid lobule contains 20 to 40 round to oval follicles, measuring 30 to 500 microns in diameter [8]. Each thyroid follicle is lined by cuboidal epithelial cells and contains a central store of colloid secreted by the epithelial cells under the influence of the pituitary hormone thyroid stimulating hormone (TSH) [18] [19] (Figure 2). There are about $3 \times 10^{6}$ follicles in the adult male thyroid gland [19]. The thyroid follicles are separated by a thin connective tissue stroma containing lymphatic vessel, blood vessels and nerves. The lumen of the thyroid follicle contains colloid, which is scalloped and pale in follicles with active secretory activity, densely eosinophilic in inactive follicles, and more flocculent ("like a clump or tuft of wool") and basophilic in the elderly. Table 1 describes the actions of the thyroid follicular cells.

Table 1. Actions of the thyroid follicular cells [95].

Synthesis of thyroglobulin
Iodination
Storage of thyroglobulin
Resorption of thyroglobulin
Hydrolysis of thyroglobulin
Release of thyroid hormone into the blood and lymphatics




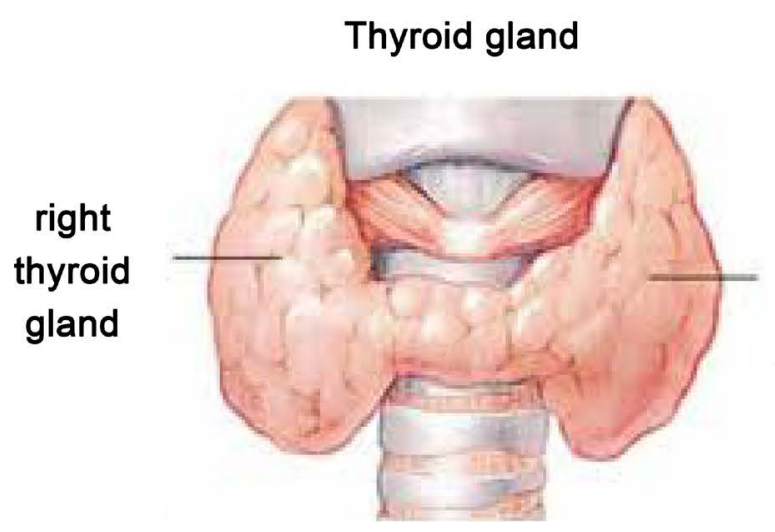

The second group of thyroid secretory cells is the parafollicular or C cells, derived from the neural crest, which contain and secrete the hormone calcitonin [8]. They are located as individual cells or clump together in small groups in the inter-follicular stroma (in the upper poles of the thyroid lobes) [8] [18] [19]. The parafollicular or $\mathrm{C}$ cells represent roughly $0.1 \%$ of the thyroid gland, identifying ten parafollicular cells per low power field in adults [20] (Figure 2). The parafollicular cells are more abundant in neonates, decrease in number adults, only to increase and appear as nodular aggregates after age 60 years [21]. The C cells have pale to clear cytoplasm, oval nuclei, and are difficult to identify with $\mathrm{H}$ and E stain, so a stain for calcitonin is used for their identification [21].

\section{Thyroid Gland Anatomy}

The thyroid gland is an extremely vascular organ that is brown to red in color, firm in consistency, located posterior to the strap muscles, and anteriorly in the lower aspect of the neck, extending from the level of the fifth cervical vertebra down to the first thoracic vertebra [18] [19]. The shape of the thyroid gland varies from an $\mathrm{H}$ to a $\mathrm{U}$ shape and is formed by two lateral lobes with superior and inferior poles connected by a median isthmus, with an average height of 12 to 15 $\mathrm{mm}$, overlying the second to fourth tracheal rings (Figure 3). Rarely, the isthmus may be absent, and the gland exists as two distinct lobes [19]. Each of the lateral thyroid lobes measures an average of 50 to $60 \mathrm{~mm}$ ( 8 to $10 \mathrm{ml}$ in volume), with the superior poles diverging laterally at the level of the oblique lines on the laminae of the thyroid cartilage (Figure 3). The lower poles diverge laterally at the level of the fifth tracheal cartilage. Even though the weight of the thyroid gland varies, it averages between $15 \mathrm{~g}$ to $30 \mathrm{~g}$ in adults and it is somewhat heavier in women [10] [18] [19]. The thyroid gland increases in size during menstruation and pregnancy [18].

A pyramidal lobe which is present in approximately 50\% of individuals often ascends from the isthmus or the adjacent part of either thyroid lobe (more often the left) toward the hyoid bone, to which it may be attached by a fibrous or fibromuscular band, the levator of the thyroid gland [19]. Remnants of the thyroglossal

Figure 3. The thyroid gland and its anatomic relationships.

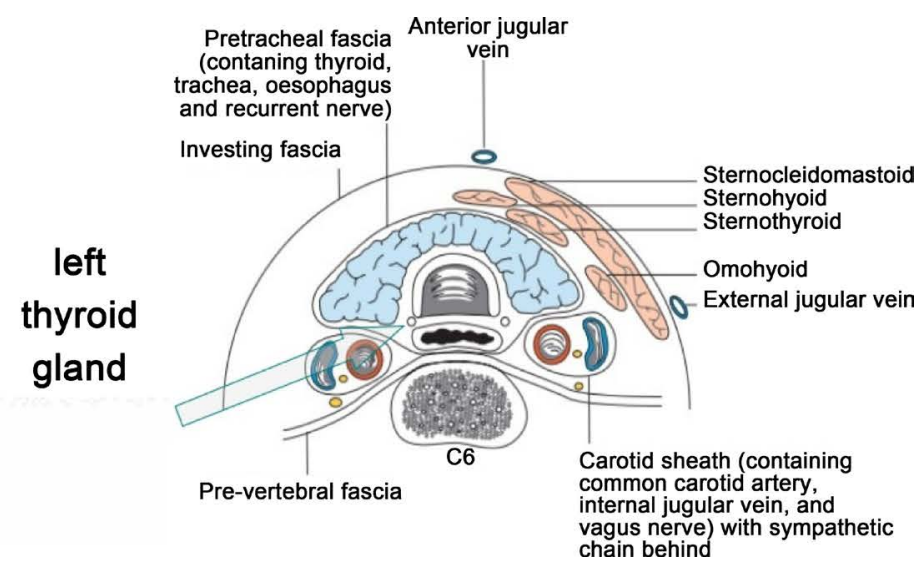


duct may endure as accessory nodules or cysts of thyroid tissue between the isthmus and the foramen cecum of the tongue base [8] [18]. Usually, two pairs of parathyroid glands lie in proximity to the thyroid gland.

The thyroid gland lies adjacent to the carotid sheaths and the sternocleidomastoid muscles laterally on each side. The lateral surface of the thyroid gland is covered by the sternothyroid muscle (Figure 2), and its attachment to the oblique line of the lamina of the thyroid cartilage prevents the superior pole from extending superiorly under the thyrohyoid muscle [8] [19]. More anteriorly are the sternohyoid and superior belly of the omohyoid muscle, covered inferiorly by the anterior border of the sternocleidomastoid muscle [18]. The sternohyoid and sternothyroid muscles are joined in the midline by an avascular fascia that must be incised to retract the strap muscle laterally in order to access the thyroid gland during thyroidectomy [8] [18]. If the strap muscles are to be transected for better exposure, it should be performed high in the neck, because the motor nerve supply from the ansa cervicalis (ansa hypoglossi) enters these muscles inferiorly [10].

The thyroid gland is enveloped by a loosely connecting fascia that is formed from the partition of the deep cervical fascia into anterior and posterior divisions [8]. The true thyroid capsule, also known as the visceral fascia, is a thin densely adherent fibrous layer that sends out septa that invaginate into the gland, forming pseudo-lobules [8]. The visceral fascia, a division of the middle layer of deep cervical fascia, attaches the thyroid gland to the laryngeal-skeleton [8] [18] [19]. This fascia condensates into two suspensory ligaments, the anterior and posterior suspensory ligaments [19]. The anterior suspensory ligament extends from the superior-medial aspect of each thyroid lobe to the cricoid and thyroid cartilage. The posterior suspensory ligament (Berry ligament) extends from the posterior-medial aspect of the gland to the side of the cricoid cartilage, and first and second tracheal rings [8] [10] [18] [19]. This firm attachment of the gland to the laryngeal-skeleton is responsible for movement of the thyroid gland and related structures during swallowing.

On its way to the larynx, the recurrent laryngeal nerve (RLN) usually passes deep to the posterior suspensory ligament (Berry ligament) or between the main ligament and its lateral leaf [19]. Deep to the ligament, but lateral to the nerve, is a posteromedial portion of the thyroid lobe, which may be overlooked during thyroidectomy.

\section{Vascular Anatomy}

The thyroid gland as well as the adrenal glands has the greatest blood supply per gram of tissue [22]. The significance is that hemostasis is a major problem of thyroid surgery, especially in patients with goiter. The arterial irrigation to the thyroid gland comes from two paired arteries, the superior and inferior thyroid arteries and, sometimes, from the thyroidea ima [8]. These arteries have abundant collateral anastomoses with each other, ipsilaterally and contra-laterally (Figure 4). The thyroid ima is a single vessel that, when present (1\% to $4 \%$ of individuals), originates from the aortic arch or the innominate artery and enters 
the thyroid gland at the inferior border of the isthmus [8] [18] [19]. Its position anterior to the trachea makes it important in tracheostomy.

The superior thyroid artery is the first anterior branch of the external carotid artery [8]. In rare cases, it may arise from the common carotid artery just before its bifurcation [8] [18]. The superior thyroid artery passes downward and anteriorly to reach the superior pole of the thyroid gland under the cover of the superior belly of the omohyoid and sternohyoid muscles. In part of its track, the artery parallels the external branch of the superior laryngeal nerve (SLN) which supplies the cricothyroid muscle and the cricopharyngeus muscle, the lowest voluntary part of the pharyngeal musculature [8]. The artery runs superficially on the anterior border of the lateral lobe, dividing into anterior and posterior branches at the apices of the thyroid lobes. These branches send branches (terminal) deep into the thyroid gland before curving toward the isthmus, where they anastomose with the contralateral artery (usually the anterior branch) [8] [19].

The superior thyroid artery has six branches: the infrahyoid, sternocleidomastoid, superior laryngeal, cricothyroid, inferior pharyngeal constrictor, and terminal branches of the artery for the supply of the thyroid and parathyroid glands [8]. There are usually two branches to the thyroid gland (anterior and posterior) but in rare instances there may be a third branch, the so-called lateral branch [8] (Figure 4 and Figure 5). The anterior branch anastomoses with the contralateral artery [23], the posterior branch anastomoses with the ipsilateral inferior thyroid artery [8]. The posterior branch gives off a small parathyroid artery which supplies the superior parathyroid gland in $45 \%$ of the cases [8] [24]. Nobori et al. [24] noted that in $67 \%$ of the cases the superior parathyroid glands received their blood supply from a single vessel, and in $1 / 3$ of the cases two or more branches reached the superior parathyroid glands.

High ligation of the superior thyroid artery during thyroidectomy places the external branch of the SLN at risk of inadvertent injury, which would produce dysphonia by altering pitch regulation [25]. The cricothyroid artery, a potentially troublesome branch of the superior thyroid artery, runs superior to the upper
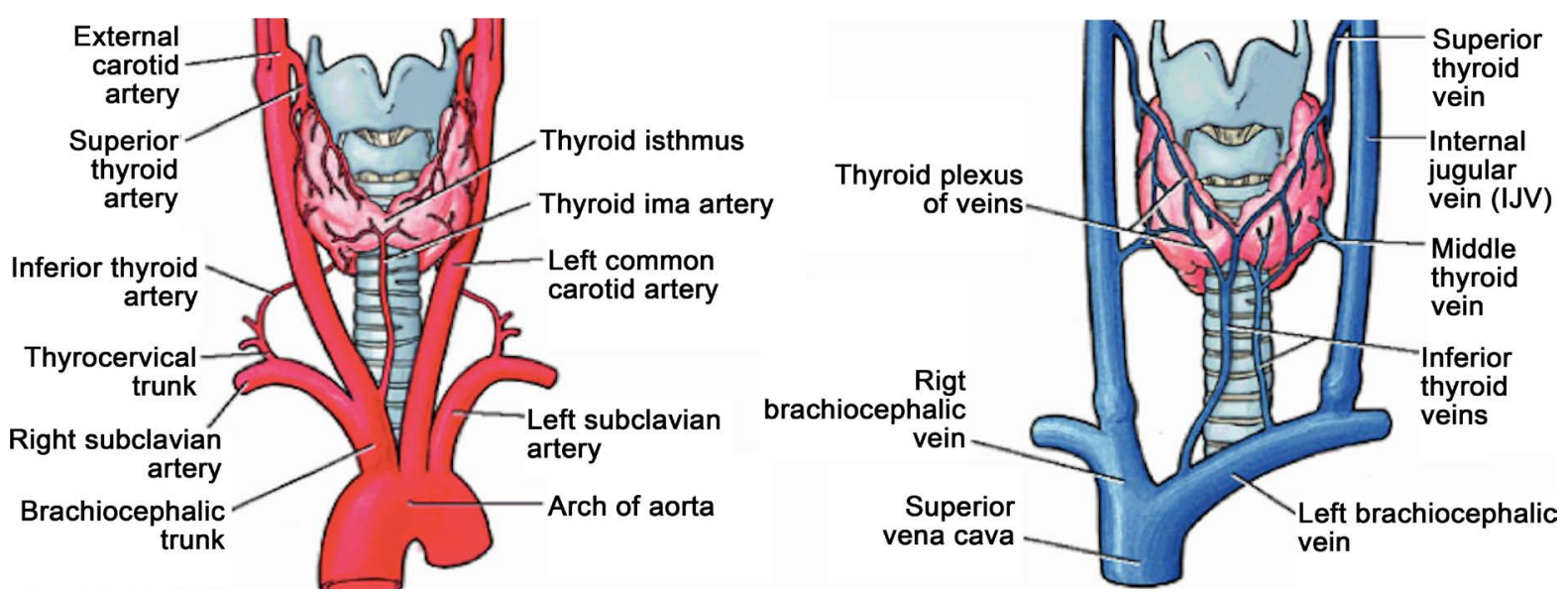

Figure 4. Arterial supply of the thyroid gland and venous drainage of the thyroid gland. 


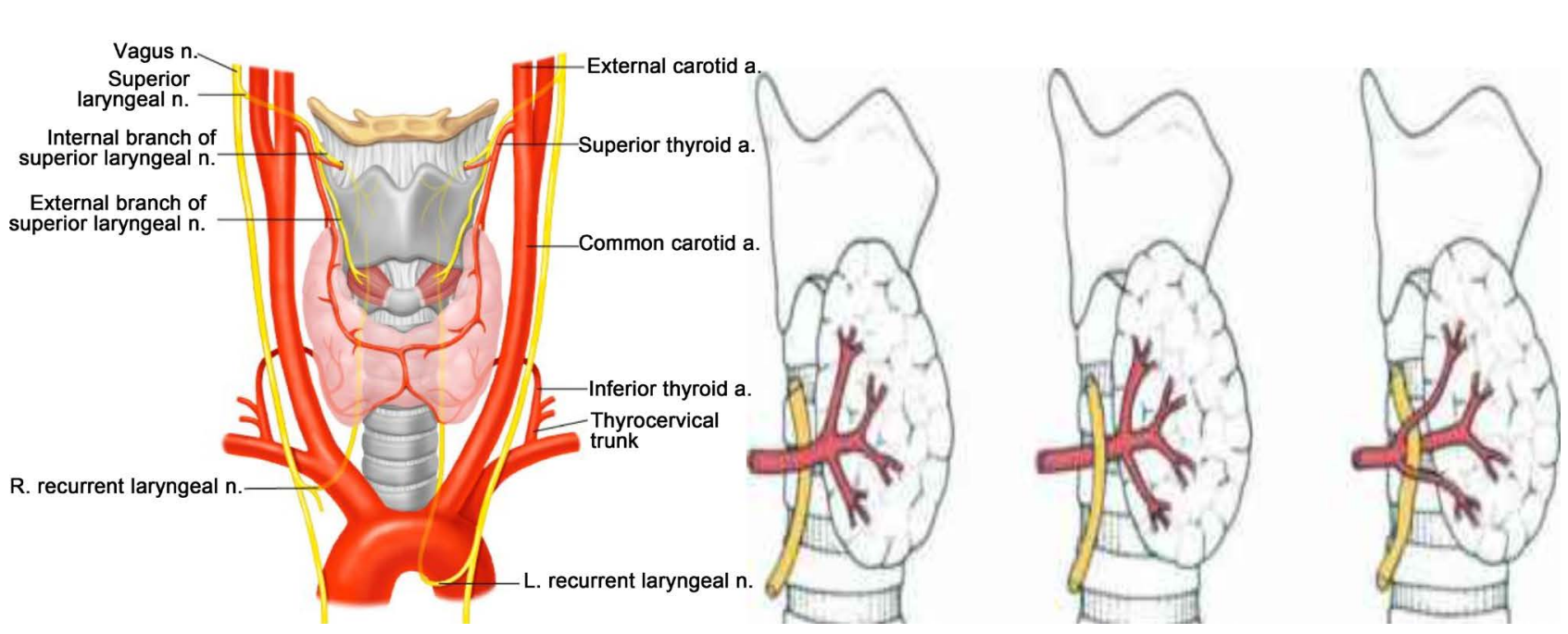

Figure 5. Anatomy of the recurrent laryngeal nerve and its relationship of the inferior thyroid artery and recurrent laryngeal nerve.

pole and runs toward the midline on the cricothyroid ligament [8]. This vessel can be lacerated during emergent cricothyroidotomy.

The inferior thyroid artery usually arises from the thyrocervical trunk (Figure 4), a branch of the subclavian artery [18] [19], but in 15\% of individuals it may arise from the subclavian artery [8]. The inferior thyroid artery ascends vertically behind the carotid sheath curving medially and posteriorly on the anterior surface of the longus coli muscle before entering the tracheoesophageal groove [8] [18] [19]. After penetrating the prevertebral fascia, the artery divides into two or more branches as it crosses the RLN. The lowest branch sends a tinny branch to supply the inferior parathyroid gland and supplies the lower pole of the thyroid gland [8]. The upper branch of the inferior thyroid artery supplies the posterior surface of the gland, usually anastomosing with the descending branch of the superior thyroid artery (posterior branch) [8]. On the right-hand side the inferior thyroid artery is absent in approximately $2 \%$ of individuals, on the left-hand side it is absent in 5\% of the cases [8] [26]. A duplicated artery is a rare occurrence [27].

The RLN ascends in the tracheoesophageal groove and enters the larynx between the inferior cornu of the thyroid cartilage and the arch of the cricoid cartilage [18] [19] (Figure 5). The RLN can be found after it emerges from the superior thoracic outlet, in a triangle bounded laterally by the common carotid artery, medially by the trachea, and superiorly by the thyroid lobe. The relationship between the inferior thyroid artery and the RLN is highly variable, as established by the work of Reed A.F. [28], who in 1943 described 28 variations in this relationship. The RLN can be found deep to the inferior thyroid artery ( $40 \%$ of the cases), superficial to the RLN (20\% of the cases), or between the branches of the inferior thyroid artery (35\% of the cases) [28] [29] [30]. Notably, the association between the RLN and the inferior thyroid artery on one side of the neck is comparable to that found on the other side in only $17 \%$ of individuals [28]. Furthermore, at the level of the inferior thyroid artery, branches of the RLN that are 
extra laryngeal may be present in 5\% of the cases [18] [28] [29]. Preservation of all of those branches is very important during thyroid surgery.

Veins of the thyroid gland form a plexus of vessels lying in the substance and on the surface of the gland [19]. The plexus is drained by three pairs of veins that provide venous drainage for the thyroid (Figure 4). The superior thyroid vein accompanies the superior thyroid artery. As it emerges from the superior pole of the thyroid gland, the vein passes superiorly and laterally across the superior belly of the omohyoid muscle and the common carotid artery to enter the internal jugular vein alone or with the common facial vein [8]. The middle thyroid vein arises on the lateral surface of the thyroid gland at about two-thirds of its anteroposterior extent. It crosses the common carotid artery following a direct course to the internal jugular vein (no artery escorts it) [8] [18]. This vein may be absent or, in very rare occurrences it may be double [8]. The extra vein is inferior to the normal vein (fourth thyroid vein). The importance of these thyroid veins is in their vulnerability during thyroid surgery. The inferior thyroid veins are the largest and most variable of the thyroid veins (the right and left side are usually asymmetric) [8]. They follow different pathways on each side. The right inferior thyroid vein passes anterior to the innominate artery to drain into the right brachiocephalic vein, rarely in may cross anterior to the trachea and drain into the left brachiocephalic vein [18]. The left vein crosses the trachea to enter the left brachiocephalic vein [18]. Sporadically, both inferior thyroid veins form a common trunk called the thyroid ima vein, which empties into the left brachiocephalic vein [8] [18] [19].

\section{Lymphatic Anatomy}

The lymphatic drainage of the thyroid gland is extensive and flows in a multidirectional pattern (Figure 6). The Hollinshead pattern of drainage is divided into four distinct patterns: median superior drainage, median inferior drainage, right/left lateral drainage, and posterior drainage [8] [31].

The median superior drainage is through three to six lymphatic vessels that arise from the superior margin of the isthmus and from the upper medial margin of the lateral lobes. These lymphatic vessels travel upwards towards the larynx to end up in the diagastric nodes. Some of the lymphatics may drain into one or two of the pre-laryngeal (Delphian) nodes just above the isthmus [8] [31]. The secondary echelon is to the upper jugular nodes on either side of the neck or to pre-tracheal nodes below the thyroid through lymphatic channels that travel from the Delphian nodes downward over the anterior aspect of the thyroid gland [8] [31].

The median inferior drainage occurs through several lymphatics vessels that drain the inferior aspect of the isthmus and the lower medial portions of the lateral lobes [9] [31]. Theses lymphatics channels follow the inferior thyroid veins to end in the pre-tracheal and brachiocephalic nodes [8] [18]. The right and left lateral drainage pattern originate from lymphatic trunks from the lateral border of each lobe [8] [31]. Superiorly the ascend with the superior thyroid artery and vein, inferiorly they follow the inferior thyroid artery [18] [31]. Between these 


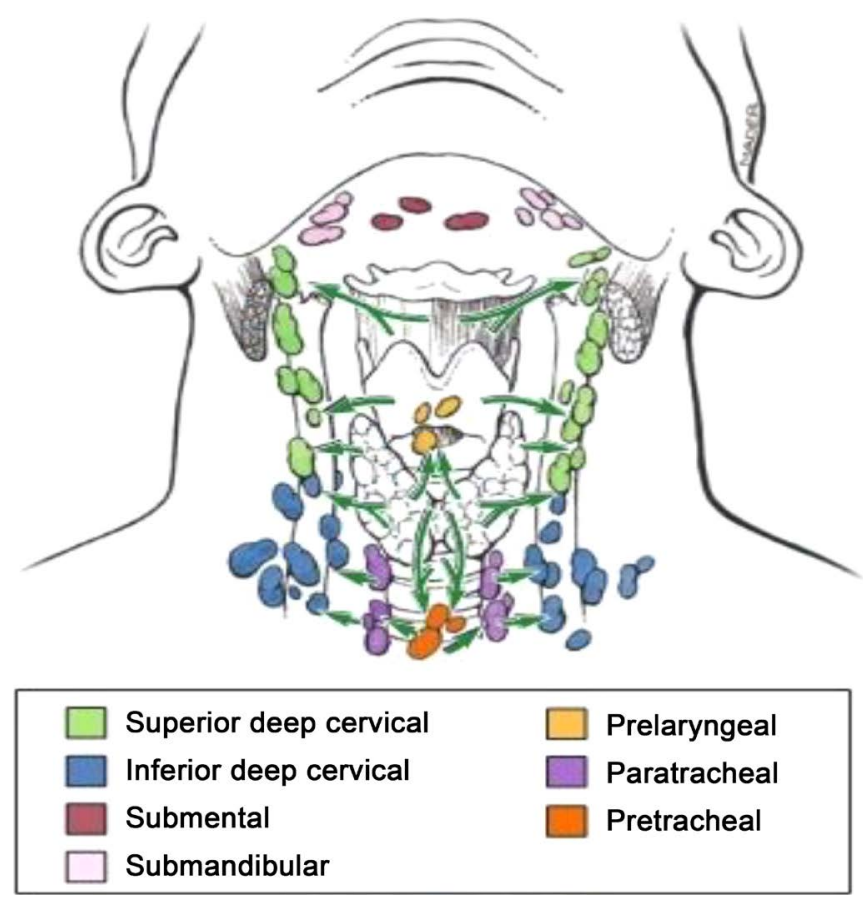

Figure 6. The lymphatic drainage of the thyroid gland is extensive and flows in a multidirectional pattern.

two groups, the lymphatic channels travel laterally, anteriorly, or posteriorly to the carotid sheath to reach the lymph nodes of the internal jugular vein [8] [18] [19] [31]. In rare instances these lymphatic vessels drain directly in to the subclavian vein, jugular vein, or thoracic duct without circulating through a lymph node [32].

The posterior drainage pattern occurs through lymphatic vessels that drain the inferomedial surfaces of the lateral lobes to drain into lymph nodes along the track of the RLN [8] [31]. Occasionally, a posterior ascending lymphatic trunk from the upper part of the lobe reaches the retropharyngeal nodes [31].

Several patterns of lymphatic drainage of the thyroid gland have been proposed, each is correct and conceptualized from the same fact. Another simplified pattern of drainage is the following: immediate lymphatic drainage goes to the peri-glandular nodes; to the pre-laryngeal (Delphian), pre-tracheal, and para-tracheal nodes along the RLN; and then to mediastinal lymph nodes [18] [19]. Regional metastases of thyroid cancer can also be found laterally, higher in the neck along the internal jugular vein. This can be explained by tumor invasion of the pre-tracheal and para-tracheal nodes causing an obstruction of normal lymph flow.

\section{Innervation of the thyroid gland}

The thyroid gland is innervated by the autonomic nervous system (ANS). The sympathetic innervation of the thyroid gland is through the superior, middle, and inferior ganglia of the cervical chain [8]. In thyroid surgery the superior laryngeal nerve and the RLN (parasympathetic/vagus), which do not innervate the thyroid gland, are of extreme importance. The risk of injury to the RLN is di- 
rectly related to the level of knowledge about the anatomy of the head and neck and the expertise of the head and neck surgeon. The functions of the larynx are to protect the lower airway, phonation, and generation of a high intrathoracic pressure for coughing and lifting [33].

The RLN (inferior laryngeal nerves) originate from the VI branchial arch [33]. These nerves arise from the vagus nerves under the VI aortic arch. Afterwards the $\mathrm{V}$ and the distal portion of the VI aortic arch regress, on both the right and left side, and the two laryngeal nerves remains attached to the structures that develop from the IV aortic arch (i.e., the right subclavian artery and the aortic arch on the left side). As the heart descends into the thorax, these arteries take with them the nerves, which then assume their normal recurrent course (Figure 5).

Galen was the first to document the presence of the RLN and he was also the first to establish that the function of the larynx was to generate voice [34]. The RLN is variable in size ranging from $1.5 \mathrm{~mm}$ to $4 \mathrm{~mm}$ in diameter [12]. Macroscopically the RLN is whitish in appearance and can have a flattened or rounded surface [8] [12] [18] [19] (Figure 5). The RLN predominantly provides the motor supply to the intrinsic laryngeal muscles and sensory innervation to the infraglottis [35]. The superior laryngeal nerve (SLN) predominantly provides the sensory supply to the supraglottis and glottis, but its external branch also provides the motor supply to the cricothyroid muscle [36]. The ansa Galeni, an anastomosis between the SLN's internal branch and one of the RLN's branches (usually the posterior branch of the RLN contributes to the anastomosis; however, the anterior branch can also contribute), provides the accessory motor and predominant sensory supply to endolaryngeal structures [36]. The "human communicating nerve" ( $\mathrm{HCN}$ ) is an anastomosis between the external branch of the SLN and the distal RLN, it is found in approximately $3 \%$ to $68 \%$ of the cases [37] [38] [39]. The HCN may contain both sensory innervation to the larynx and motor innervation to the thyroarytenoid muscle [37] [38] [39].

The right RLN branches from the vagus nerve (cranial nerve $\mathrm{X}$ ) as it crosses anterior to the right subclavian artery, looping around the subclavian artery from posterior to anterior, passing behind the right carotid sheath and ascending in the right tracheoesophageal groove [8]. It courses posterior to the right thyroid lobe to enter the larynx behind the cricothyroid articulation and the inferior cornu of the thyroid cartilage (Figure 5). The left RLN originates from the left vagus nerve at the point where the nerve crosses the aortic arch, looping under the ligamentum arteriosum and the aorta, ascending in the left tracheoesophageal groove [8]. Both nerves cross the inferior thyroid arteries near the lower border of the middle third of the gland.

The entry point of the RLN into the larynx is just behind and below the cricothyroid joint [8]. At this level, it is protected by the inferior pharyngeal constrictor muscle and the cricothyroid muscle [40]. In approximately $90 \%$ of the cases, the RLN divides into two to three branches just a few millimeters before 
entering the larynx underneath the inferior pharyngeal constrictor muscle [40]. The branching of the RLN outside the larynx can occur at any point along the course of the nerve but it is unusual below the inferior thyroid artery [41]. Classically, the extra laryngeal branches of the RLN were described as functionally discrete fibers, separated into the anterior and posterior branches, where the anterior branches exclusively innervated the adductor muscles (lateral cricoarytenoid, interarytenoid, and thyroarytenoid), whereas the posterior branches innervated the abductor muscles (posterior cricoarytenoid) [42] [43]. Nevertheless, other studies have described no consistent functional pattern of branching of the anterior and posterior laryngeal branches [42] [43].

The RLN innervates the four intrinsic muscles of the larynx (lateral cricoarytenoid, posterior cricoarytenoid, transverse and oblique interarytenoid and thyroarytenoid) but it does not provide innervation to the cricothyroid muscle (Figure 7) [8] [18] [19] [30]. The interarytenoid muscle, the only unpaired muscle of the larynx, receives innervation from both RLNs [30] [40]. Before entering the larynx, the RLN also sends branches to the inferior pharyngeal constrictor muscle and cricopharyngeus muscle [8] [18] [19] [30] [40]. As mentioned previously the RLN provides sensory innervation to the mucosa of the infraglottis [36].

The RLN is at risk of injury during thyroid surgeries. Even though disagreement still surrounds whether the recognition of the RLN during thyroid surgery will influence the incidence injury, most surgeons encourage the identification and dissection of the nerve during the procedure to reduce the risk of injury [41]. Some surgical landmarks have been recommended to identify the RLN during thyroid surgery, including the relation of the nerve to inferior thyroid artery, the relation of the RLN to the tracheoesophageal groove, the relation of the RLN to Berry's ligament, and the relation of the nerve to Zuckerkandl's tubercle.

The association that exists between the RLN and inferior thyroid artery is variable [44] [45]. As mentioned previously Reed A.F. [28] described 28 variations in this relationship. In his paper the RLN can be found deep to the inferior thyroid artery ( $40 \%$ of the cases), superficial to the RLN ( $20 \%$ of the cases), or between the branches of the inferior thyroid artery (35\% of the cases) [28] [29] [30]. Notably, the association between the RLN and the inferior thyroid artery on one side of the neck is comparable to that found on the other side in only $17 \%$ of individuals [28]. Steinberg et al. [44] reported that the RLN courses in the neck between the branches of the inferior thyroid artery in about $6.5 \%$ of individuals, posterior to the inferior thyroid artery in $61.5 \%$ of individuals, and anterior to the inferior thyroid artery in $32.5 \%$. On the right-hand side, the RLN may be in any of three locations in relation to the artery [44] [45] (Figure 8). On the left-hand side, it is more likely to lie posterior to the artery [44] [45] (Figure 8).

The RLN is commonly found near the posterior suspensory ligament (Berry's ligament), with the vast majority of the nerves found within three millimeters 

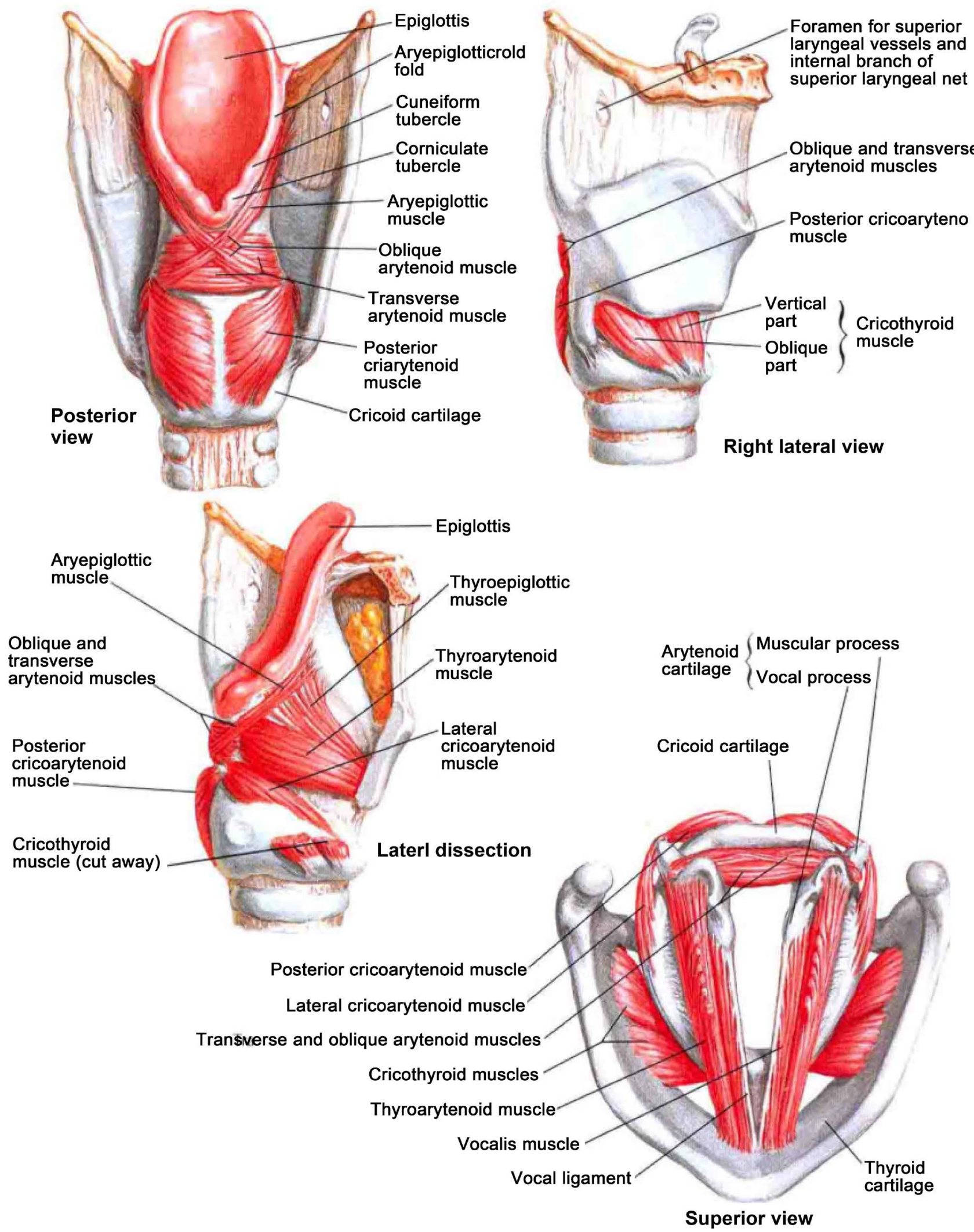

Figure 7. Intrinsic muscles of the larynx. 

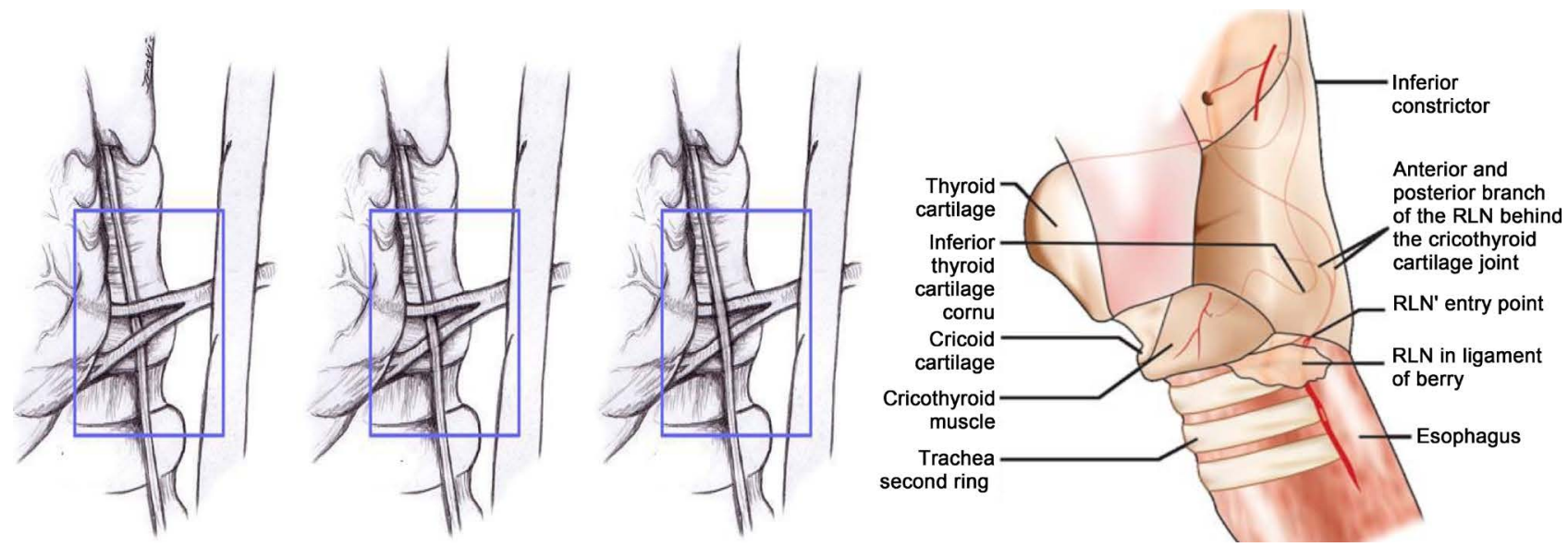

Figure 8. Variants in the association between inferior thyroid artery and RLN and the RLN found posterior to the posterior suspensory ligament.

[35]. There have been some descriptions were the RLN penetrates through the posterior suspensory ligament [8] [46] (Figure 8), but in the majority of cases (45\%), the RLN is superficial (dorsolateral) to the Berry's ligament [47].

The distal end of the RLN can be seen along the tract of the tracheoesophageal groove [30]. The RLN can be localized more reliably at the cricothyroid articulation. Shindo et al. [30] reported that most of the RLNs on the right-hand side course between $15^{\circ}$ to $45^{\circ}$ when entering the cricothyroid joint, while most of the RLNs on the left-hand side course between $0^{\circ}$ to $30^{\circ}$, this difference is secondary to the more angled track the right RLN takes when ascending in the neck. The most common direction of the right and left RLN was type II $\left(15^{\circ}\right.$ to $\left.30^{\circ}\right)$, the next common route on the right hand-side was a type III $\left(30^{\circ}\right.$ to $\left.45^{\circ}\right)$ and on the left-hand side was a type $\mathrm{I}\left(0^{\circ}\right.$ to $\left.15^{\circ}\right)$ [30].

The tubercle of Zuckerkandl is characterized as being a thickening in the thyroid gland where the ultimobranchial body merges with the median thyroid anlage and can enlarged to become a nodular process [48]. When enlarged, it is a reliable landmark for the RLN because the nerve almost always courses medial and deep to it [15].

A non-recurrent laryngeal nerve is a very rare finding, $0.5 \%$ to $1 \%$ of the cases [8] [18] [19] [35]. It is associated with an aberrant right subclavian artery, arising from the aorta after the left subclavian artery has given off [8]. In these circumstances the right RLN passes directly from the vagus nerve in the neck towards the larynx and does not recur around subclavian artery (Figure 9). This uncommon anatomic variation of the right RLN makes it highly susceptible to surgical injury. A left non-recurrent laryngeal nerve is extremely rare [8].

The SLN arises from the vagus nerve below its lower sensory ganglion (inferior ganglion) just outside the jugular foramen of the skull [8]. The nerve descends lateral to the pharynx, at first posterior and then medial to the internal carotid artery (ICA). At the level of greater cornu of hyoid bone, the SLN divides into a smaller external branch (motor) and a larger internal branch (sensory) [8] [49]. The point of division is usually within the bifurcation of the common 


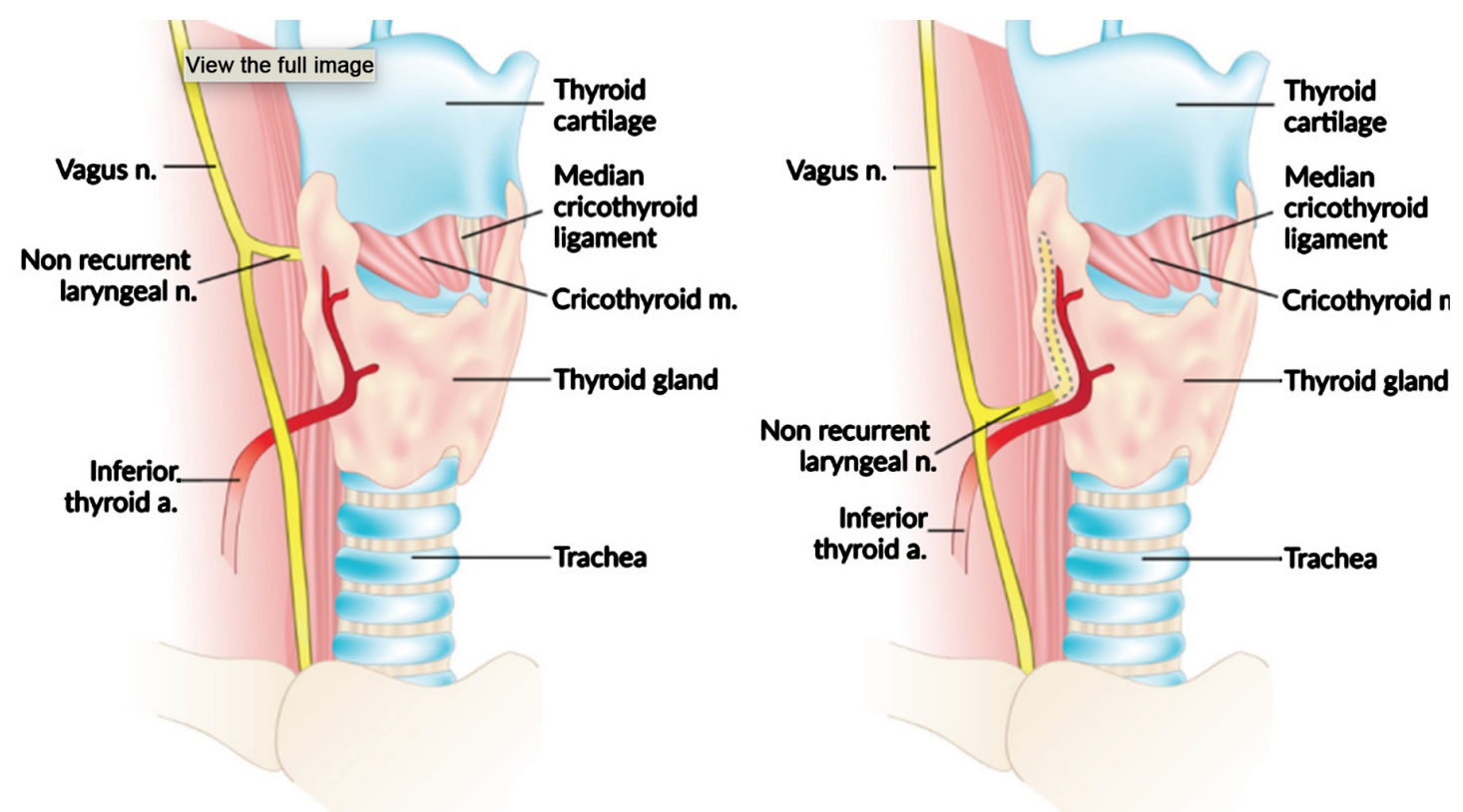

Figure 9. A non-recurrent laryngeal nerve originating from the vagus nerve above and below the laryngeal tracheal junction.

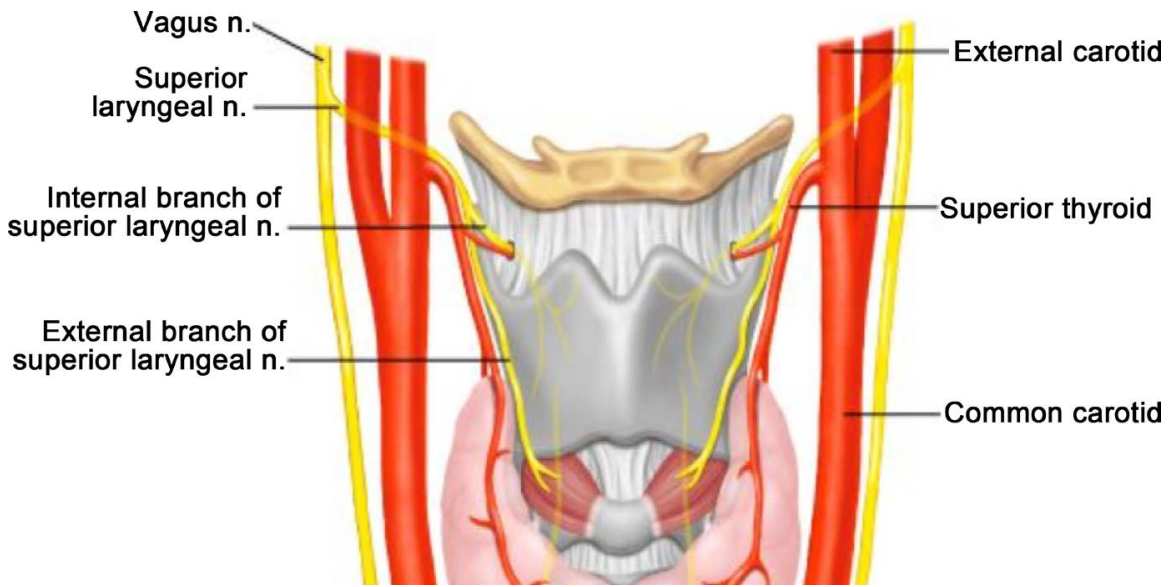

Figure 10. Branching of the superior laryngeal nerve (SLN).

carotid artery (Figure 10).

The larger internal branch of the SLN crosses the external carotid artery above or below the origin of the lingual artery, or in rare cases the nerve may divide medial to the external carotid artery [50]. The internal branch of the SLN pierces the thyrohyoid membrane above the entrance of superior laryngeal artery (branch of the superior thyroid artery). The internal branch SLN divides into an upper branch and a lower branch. The upper branch supplies the mucous membrane of lower part of pharynx, epiglottis, vallecula, and vestibule of the larynx. The lower branch descends in the medial wall of the pyriform fossa beneath the mucous membrane. It supplies the aryepiglottic fold and the mucous membrane of the larynx up to the level of the vocal folds. The internal branch SLN provides general sensation, including pain, touch, and temperature for the tissue superior 
to the vocal folds. The internal branch SLN is vulnerable during surgical interventions of the anterior cervical region, including carotid endarterectomy and cervical spine surgery, with an anterior or anterolateral approach [51]. Since the nerve passes beneath the mucous membrane of the medial wall of the piriform fossa, it is accessible for injection of local anesthesia, thus providing excellent anesthesia for most of the piriform fossa [52].

The smaller external branch of SLN descends to the region of the superior pole of the thyroid gland and courses medially along the inferior pharyngeal constrictor muscle, passing under the sternothyroid muscle, alongside the superior thyroid vein and artery (passes posterior and medial to the vessels) [8]. The external branch of SLN supplies the cricothyroid muscle, which is the only tensor muscle of the vocal cords [37]. In addition to its contribution to phonation, the cricothyroid muscle plays a role in the overall regulation of breathing by its control of expiratory resistance and flow [53]. The nerve enters the cricothyroid muscle laterally on its deep surface. The external branch of SLN also contributes innervations to the pharyngeal plexus, which innervates the palate and pharynx, and is formed by the external branch of SLN, pharyngeal nerves, branches from the cranial nerve IX, and the sympathetic trunk [18] [19].

In roughly $20 \%$ of individuals, the external branch of the SLN is under the inferior pharyngeal constrictor muscle and cannot be visualized, but it can be stimulated using a nerve probe [10]. The external branch of the SLN is closely related with the superior thyroid vascular pedicle at the capsule of the superior pole of the thyroid [10] [12]. Due to the close anatomical relationship, the external branch of the SLN is at risk of injury during thyroid surgeries. Numerous anatomical variations exist between the course of the external branch of the SLN, the superior thyroid artery, and the superior pole of the thyroid [8] [54]. Cernea et al. [54] [55] depicted the level at which the external branch of the SLN crosses behind the superior thyroidal artery (Table 2).

\section{Thyroid Gland Physiology}

\section{Iodine Metabolism}

Iodine is a vital micronutrient that can be obtained only via dietary sources [56] [57]. It circulates in the bloodstream in its ionized form, iodide (I-) and is a key ingredient for thyroid hormone synthesis, accounting for $65 \%$ of the molecular weight of T4 (thyroxine) and 59\% of T3 (triiodothyronine) [56]. In order

Table 2. Classification of the external branch of the superior laryngeal nerve (SLN) [54].

Classification of the External Branch of the SLN [54].

Type 1: External branch of the SLN crosses the superior thyroid vessels $1 \mathrm{~cm}$ or more above a horizontal plane passing through the upper border of superior thyroid pole.

Type 2a: The nerve crosses the vessels less than $1 \mathrm{~cm}$ above the plane.

Type 2b: The nerve crosses the vessels below the plane.

- Cernea type $2 \mathrm{~b}$ is the most common position.

- Cernea type $2 \mathrm{~b}$ nerves are also the most vulnerable to injury during thyroidectomy [55]. 
to provide the adult thyroid gland with the $60 \mu \mathrm{g}$ of I- per day required to synthesize normal amounts of thyroid hormone, the recommended daily intake of iodine is roughly 150 micrograms [58], which can be obtained from foods such as fish, milk, eggs, or as additives in bread or salt [57] [59]. Under normal physiologic conditions, the thyroid gland contains more than $90 \%$ of the total body I-, with an I- concentration 20 to 40 times higher than that of the serum [60].

In the proximal gastrointestinal tract (stomach and jejunum), iodine is promptly converted to its ionized form, iodide (I-), and absorbed into the bloodstream, and from there it is distributed uniformly throughout the extracellular compartment. I- is actively transported into the thyroid follicular cells by an adenosine triphosphate (ATP) dependent process [61]. The $\mathrm{Na} / \mathrm{I}$ - symporter (NIS) located on the basolateral plasma membrane of the thyroid follicular cells (which contain 13 transmembrane segments) is responsible for the active transport mechanism [60] [62]. It exploits the inwardly directed $\mathrm{Na}+$ gradient generated by the $\mathrm{Na}+/ \mathrm{K}+$ ATPase to couple movement of $\mathrm{Na}+$ and $\mathrm{I}-$ from the blood into the thyroid follicular cell cytoplasm [60]. Two $\mathrm{Na}+$ ions enter for every I-, and this 2:1 stoichiometry generates a positively charged inward current [56] [62]. The activity of the NIS and uptake of I- are regulated by thyroid-stimulating hormone (TSH) and by I- itself [62]. As mentioned previously the thyroid gland stores more than $90 \%$ of the body's I- content and accounts for only one third of the plasma I- loss [60]. The remaining plasma I- is cleared via renal excretion, approximately $90 \%$ of ingested iodine is excreted in the urine [56] [63] [64].

As soon as the I- molecule enters the thyroid follicular cell, an electrochemical gradient propels the I- molecule to the apical surface of the thyroid follicular cell. The mechanism of the efflux of I- from the cell cytoplasm into the thyroid follicular lumen is less well characterized. A transmembrane protein, Pendrin, is believed to play a role in the apical I- transport [56] [60] [62] [65], which is mutated in Pendred's syndrome, leading to a partial defect in the organification of iodide. Pendred's syndrome is characterized by hereditary sensorineural deafness and rarely euthyroid goiter [56] [60] [62] [65].

\section{Thyroglobulin}

Thyroglobulin is the most highly expressed protein in the thyroid gland and it is synthesized by the thyroid follicular cells [66]. Thyroglobulin it is one of the largest proteins in the human body, having a molecular weight of $660 \mathrm{kDa}$, and consisting of a signal peptide sequence of approximately 2750 amino acid residues [66] [67]. It has a homogeneous structure consisting of four distinct regions: three cysteine-rich repetitive domains ( $\mathrm{Tg} 1, \mathrm{Tg} 2$, and $\mathrm{Tg} 3$ ) and the cholinesterase-like (ChEL) domain (C-terminus of the molecule), which is highly homologous to acetylcholine [66] [68].

The synthesis of thyroglobulin is regulated by TSH and by various transcription factors, including thyroid transcription factor 1 (TTF-1), TTF-2, and paired box gene 8 (Pax-8) [66]. Thyroglobulin molecules undergo oxidation (part of the 
folding process), glycosylation and dimerization [66] [68]. Several molecular chaperones, including BiP, GRP94, ERp29, GRP170, ERp72, and calnexin, are involved in the maturation of thyroglobulin and act as intracellular quality control to ensure that only properly folded and glycosylated thyroglobulin molecules are ultimately released [57] [66] [67]. The process is somewhat protracted, with a half-life of 90 minutes to 120 minutes for newly synthesized thyroglobulin to arrive at the Golgi complex [69]. In the Golgi apparatus it is incorporated into exocytic vesicles that migrate to the apical membrane of the follicular cell, where the organification and coupling process takes place [57] [66].

\section{Organification and Coupling}

Even though organification and coupling are often discussed as discrete steps, both reactions are catalyzed by thyroid peroxidase (TPO) and occur concurrently [60]. The process by which oxidized iodide attaches to tyrosyl residues on the thyroglobulin molecule is referred to as organification. These process leads to the formation of monoiodotyrosine (MIT) or diiodotyrosine (DIT) residues, still located within the thyroglobulin molecule [57] [60]. Of the 132 to 140 tyrosyl residues in each molecule of dimerized human thyroglobulin (the reported number differs because of modifications in complementary DNA (cDNA) sequencing), only a small subset, are truly susceptible to iodination [57] [60] [68] [70]. Although each molecule of mature thyroglobulin contains five to 50 iodine atoms, only some iodinated sites are ultimately involved in hormonogenesis because of their spatial orientation [57] [60].

After the formation of MIT and DIT residues, the coupling reaction transpires: two DIT residues combine to form T4 (tetraiodothyronine) or one MIT combines with one DIT to create T3 (triiodothyronine) [57] [60]. Figure 11 shows the molecular structures of $\mathrm{T} 4$ and $\mathrm{T} 3$. In this reaction, also catalyzed by TPO and mediated by hydrogen peroxide $\left(\mathrm{H}_{2} \mathrm{O}_{2}\right)$, the iodinated phenyl group of a tyrosyl residue is donated to become the outer ring of the iodothyronine acceptor site [60]. Tyrosines 5, 2554, and 2747 are the most important acceptor sites, while tyrosines 130,847 , and 1448 are the dominant donors [60] [70]. Roughly one third of T4 is formed by the acceptor-donor pair of tyrosine 5 and tyrosine 130 [57]. After the coupling reaction, the newly formed T3 and T4 are still incorporated within the thyroglobulin molecule [57]. Under normal circumstances (normal iodine supply and normal thyroid function), the typical thyroglobulin molecule contains 2.5 residues of T4, 0.7 of T3, 4.5 of DIT, and 5 of MIT [57].

\section{Secretion and Storage}

As soon as organification and coupling are complete, the iodinated, mature thyroglobulin is released into the follicular lumen, where it makes up more than $95 \%$ of the colloid [57] [71]. Roughly two thirds of the thyroglobulin found in the colloid is in the soluble $660 \mathrm{kDa}$ dimerized form, but free monomers and tetramers are also found in minimal amounts [57] [71]. The additional $34 \%$ of the thyroglobulin molecules exists in a dense, highly concentrated insoluble form (i-Tg), with high iodine content but with virtually undetectable thyroid hormonel 

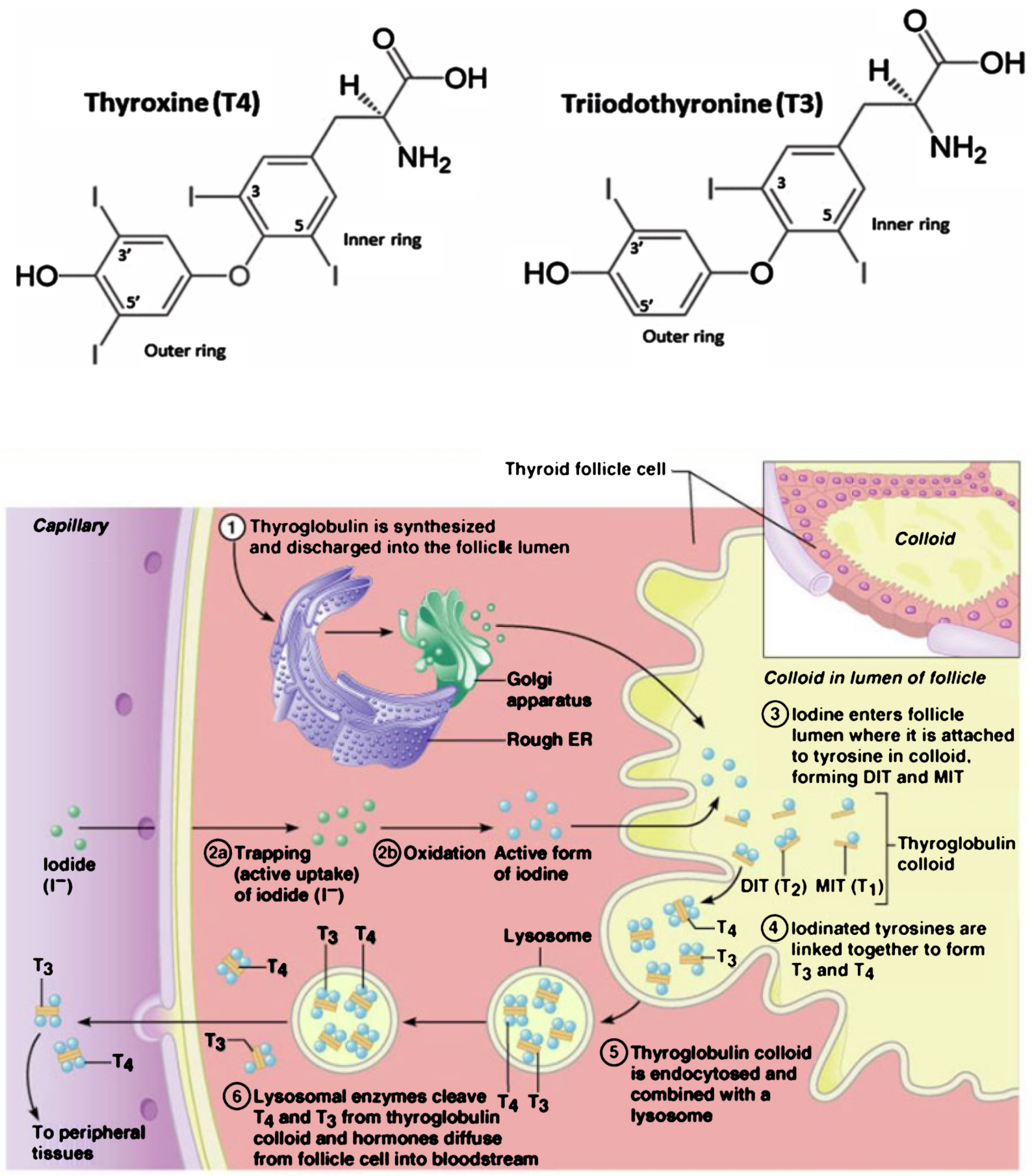

Figure 11. Molecular structure of T4 and T3 and thyroid hormone synthesis.

residues [57] [64] [71]. When the thyroid follicular cells are stimulated by thyroid stimulating hormone (TSH), thyroglobulin is mobilized from the colloid and returns to the thyrocyte via a process called micropinocytosis. Because of their physical juxtaposition to the apical membrane and solubility, newly secreted thyroglobulin molecules are taken up first [64] [71] [72]. Pits coated by clathrin are formed on the luminal side of the apical membrane of the thyrocytes and help internalize the thyroglobulin molecule. The pits then invaginate to 
form intracellular vesicles, which shed their clathrin coats and quickly fuse with early endosomes [57] [71] [73]. This complex process is thought to transpire via a combination of nonspecific fluid phase uptake (likely the main route of thyroglobulin uptake leading to degradation and release of thyroid hormones) and receptor mediated uptake (which appears to lead to other post endocytic pathways) [57] [71] [74].

The intracellular thyroglobulin molecules follow one of at least three different pathways: proteolytic destruction into its component parts, recycling back to the follicular lumen, or transcytosis [57] [71] [74]. In the first pathway, thyroglobulin travels through the endosomal system to lysosomes, where MIT, DIT, T4, and $\mathrm{T} 3$ residues are selectively removed from the molecule [57] [75]. The free MIT and DIT residues released from lysosomes cannot merge to synthesize T\$ or T3; rather, they are deiodinated to produce iodide (I-) and tyrosine, both of which are then reused for novel thyroglobulin synthesis and organification. The chief enzyme responsible for this iodide recycling process is iodotyrosine dehalogenase 1 (DEHAL 1), an NADPH dependent transmembrane protein located at the apical membrane of follicular cells [76] [77]. Lastly, cathepsins D, B, and $\mathrm{L}$, which are lysosomal proteases, act at specific cleavage sites on thyroglobulin to produce hormone enriched polypeptides. These are then further hydrolyzed by exopeptidases (lysosomal dipeptidase I) to release free thyroid hormones into the cytoplasm [78] [79].

Traditionally, the secretion of thyroid hormones into the bloodstream has been credited to passive diffusion, but more recent evidence corroborates a transport system located at the follicular thyroid cell basolateral membrane. Transmembrane thyroid hormones transporters, particularly monocarboxylate transporter 8 (MCT8) and OATP1C1 (a member of the sodium independent organic anion transporting polypeptide family), have been well described in peripheral tissue. The latest studies have demonstrated immunohistochemical localization of MCT 8 to the basolateral membrane of the thyrocyte and have also suggested that MCT 8 is in fact necessary for normal thyroid hormone secretion from the thyroid gland [80] [81]. Figure 11 summarizes thyroid hormone synthesis and secretion.

\section{Thyroid Hormone Transport}

Under normal conditions, $90 \%$ of the hormone secreted by the thyroid gland is in the form of T4 and the other 10\% is T3 [82]. Most of the thyroid hormone circulates bound to serum proteins, only $0.3 \%$ of $\mathrm{T} 3$ and $0.03 \%$ of $\mathrm{T} 4$ are free in solution [83] [84]. This is reflected in the half-lives of the hormones: T3 has a halve life of about 24 hours, and T4 has a halve life of about 6 to 7 days [84]. The majority of the thyroid hormone circulates bound to carrier proteins, with $95 \%$ bound to either thyroid binding globulin (TBG), transthyretin (TTR), or albumin. TBG has the highest affinity for thyroid hormone and is induced by estrogen and thyroid hormone. The remaining $4 \%$ to $5 \%$ is bound to other minor thyroid hormone carriers, such as lipoproteins, immunoglobulins, and lipocalins [84] [85]. Transthyretin (formerly called thyroxine binding pre-albumin or 
TBPA) is present in both serum and cerebrospinal fluid and has a somewhat lower affinity than TBG; serum albumin has a rather low affinity for thyroid hormone but is present is large amounts in serum [84] [85]. The carrier proteins serve both as a stable reservoir of extrathyroidal thyroid hormones and as a safe guard for the very hydrophobic free hormone from its aqueous environment [82] [84] [85]. As a consequence of this method of distribution and buffering, T4 has longest halve life of any hormone (6 to 7 days), and its serum concentration of $0.1 \mu \mathrm{M}$ is second only to cortisol [85].

The synthesis and release of TBG are affected by several hormones: glucocorticoids and androgens reduce the amount of TBG, while estrogens increase TBG levels, especially during pregnancy [83] [85]. These observations are of some clinical relevance for individuals being treated with thyroid hormone since the levels of exogenous thyroid hormone required will be affected by the presence of other hormones. As an example, patients with Graves' disease may have their disorder exacerbated by concurrent androgen therapy (e.g., for metastatic breast cancer).

\section{Mechanism of Thyroid Hormone Action}

Circulating free T4 and T3 can be taken up by peripheral cells at any time, and both T4 and T3 can swiftly detach from their carrier proteins to increase the availability of free hormone when necessary [82] [85]. The entry of free T4 or T3 into target cells is mediated by a variety of plasma membrane transporters, including the aforesaid monocarboxylate transporters (including MCT 8 and MCT 10) and OATP1C1, as well as the $\mathrm{Na}+$ taurocholate co-transporting polypeptide, the L type amino acid transporters (LAT1 and LAT2), and fatty acid translocase [80] [81]. Though the MCT transporters are widely expressed in most tissues, OATP1C1 is much more specific, expressed predominantly in the brain and testes [81]. The transporters also vary in their ligand specificity, with MCT 10 demonstrating increased affinity for $\mathrm{T} 3$ and OATP1C1 demonstrating strong preference for T4 [81] [86].

All known actions of thyroid hormones appear to be mediated by the thyroid hormone receptor, which is a member of the steroid hormone receptor superfamily. T3 and T4 enter cells by passive diffusion and bind a cytoplasmic binding protein. Once inside the cell, T4 is deiodinated by the iodothyronine deiodinase family of seleno proteins (Type 1, 2, 3 deiodinase) to T3, which moves to the nucleus (either facilitated by the binding protein or by diffusion) and binds to the thyroid hormone receptor [12] [82]. The outer (5')-ring deiodination of the prohormone $\mathrm{T} 4$ produces the active form of $\mathrm{T} 3$, while inner (5)-ring deiodination produces the inactive metabolite (reverse T3; rT3) [87] [88]. In general, the thyroid hormone receptors are constitutively active as repressors in the absence of hormone, although repression of gene expression can also be hormonally regulated (as in the case of the $\alpha$ and $\beta$ TSH sub-unit genes) [82]. The non-hormone binding thyroid hormone receptor- $\alpha 2$ is probably a constitutive repressor and apparently acts as a competitive inhibitor of the binding of other thyroid hor- 
mone receptor isoforms to DNA [82].

T3 can act within the nucleus, at the plasma membrane, in the cytoplasm, and at the mitochondria [89]. Genomic action, which is defined as the action of the thyroid hormones in the nuclei, involves the binding of T3 to thyroid hormone nuclear receptors (TR), which then function as T3 inducible transcription factors that upregulate the expression of thyroid hormone responsive genes [82] [89] [90]. Two major subtypes of TR have been identified, each of which has several isoforms. Located on chromosome 17, the $\operatorname{TR} \alpha$ gene encodes TR $\alpha 1$, which binds T3, as well as two other non-T3-binding products: TR $\alpha 2$ and TR $\alpha 3$ [89] [90]. TR $\alpha 1$ is constitutively expressed during embryonic development, while in postnatal life, it is predominantly expressed in brain, heart, bone, and skeletal muscle [89] [90]. There are three T3-binding TR $\beta$ isoforms encoded by the $\operatorname{TR} \beta$ gene on chromosome 3: $\operatorname{TR} \beta 1$ is expressed widely, $\operatorname{TR} \beta 2$ predominantly expressed in brain, retina, and inner ear, and $\operatorname{TR} \beta 3$ in kidney, liver, and lung [89] [90]. The phenotypic significance of this tissue- specific TR expression is still under investigation.

Regulation of Thyroid Hormone

The traditional comprehension of thyroid hormone hemostasis is founded on the negative feedback system of the hypothalamic pituitary thyroid axis (HPT axis see Figure 12) [90] [91] [92] [93]. Thyrotropin releasing hormone (TRH) neurons located in the para-ventricular nucleus of the hypothalamus $(\mathrm{PVH})$ sense the circulating levels of thyroid hormones (T4 and T3). While other regions of the hypothalamus, including the lateral and ventromedial nuclei, also express TRH, only the PVH is tightly regulated by thyroid hormones (T4 and T3) [91]. Thyroid hormones bind to the TR $\beta 2$ isoform in the $\mathrm{PVH}$ and induce TRH gene expression via a negative feedback fashion [91]. When T4 and T3 levels are high, TRH expression is low and vice versa [91] [93]. The pituitary portal system then delivers TRH to the anterior pituitary gland, where TSH (also

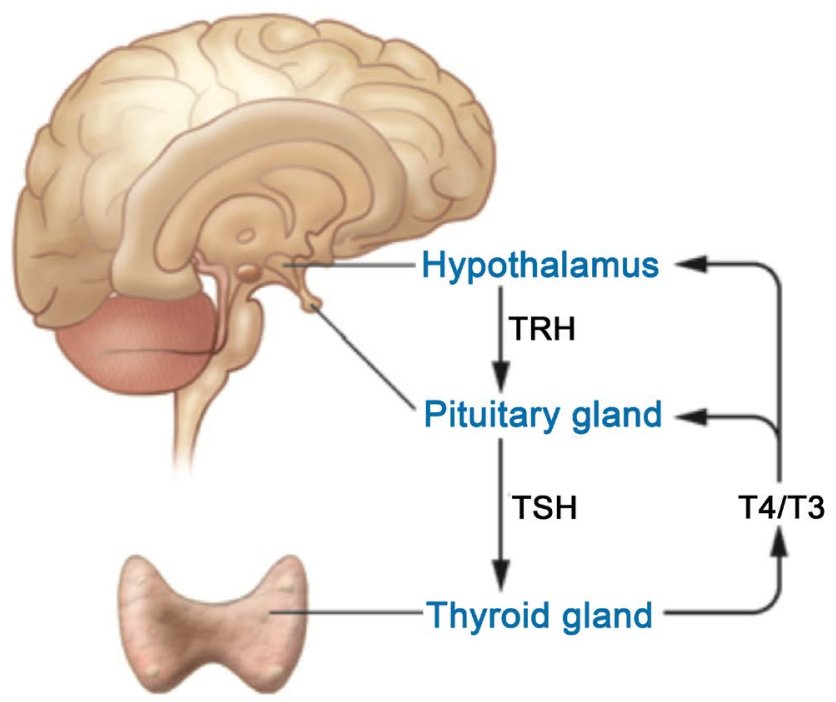

Figure 12. Hypothalamic pituitary thyroid axis. 
called thyrotropin or thyroid stimulating hormone) is synthesized and secreted. Thyroid hormones (T4 and T3) wield a negative feedback effect on this step as well. Once it is released from the anterior pituitary gland, TSH binds to TSH receptors (TSHR) on the basal membrane of the thyroid follicular cells, which activates an intracellular cascade, including the activation of adenylate cyclase [64] [92] [93]. The subsequent increase in cyclic adenosine monophosphate (cAMP) fuels nearly every step in thyroid hormone synthesis, including iodine uptake, synthesis of thyroglobulin, organification and coupling, and follicular cell uptake of thyroglobulin from the colloid [93].

An additional key component of thyroid hormone control is the availability of iodine. As formerly discussed, iodine is crucial for thyroid hormone synthesis. Iodine deficiency leads to increase in TSH secretion, which stimulates follicular growth and goiter formation [94]. The conduct of the thyroid gland under conditions of iodine excess is a little more complex. Large amounts of iodine are found in some medications, topical anti-septics, radiology contrast agents, and food preservatives [63] [94].

Iodine essentially produces an intrathyroidal negative feedback system under normal circumstances. Iodine excess inhibits its own organification, which prevents overproduction of thyroid hormones [59] [92] [94]. This is called Wolff-Chaikoff phenomenon [94]. The phenomenon is thought to be due to inhibition of TPO by intrathyroidal organic iodo compounds, but reduced intrathyroidal deiodinase activity also seems to play a role [59] [94]. The inhibition of thyroid hormone synthesis is transient, lasting anywhere between 24 to 48 hours, even with continued administration of excess iodine [59] [63] [92]. Within 24 hours after an acute iodine load, there is a decreased expression of the NIS, ensuing a reduced thyroidal uptake of iodine and resumption of normal thyroid hormone synthesis [59] [92] [94]. This, so called, escape from the Wolff-Chaikoff effect prevents development of iodine induced hypothyroidism.

\section{Conclusion}

A complete understanding of the thyroid embryology, anatomy, histology, and physiology is essential to the modern head and neck surgeon/endocrine surgeon/thyroid surgeon as they may impact the completeness of surgery as well as the complications of surgery.

\section{References}

[1] Tunbridge, W.M., et al. (1977) The Spectrum of Thyroid Disease in a Community: The Whickham Survey. Clinical Endocrinology, 7, 481-493. https://doi.org/10.1111/j.1365-2265.1977.tb01340.x

[2] Vanderpump, M.P., et al. (1995) The Incidence of Thyroid Disorders in the Community: A Twenty-Year Follow-Up of the Whickham Survey. Clinical Endocrinology, 43, 55-68. https://doi.org/10.1111/j.1365-2265.1995.tb01894.x

[3] Hollowell, J.G., et al. (2002) Serum TSH, T(4), and Thyroid Antibodies in the United States Population (1988 to 1994): National Health and Nutrition Examination 
Survey (NHANES III). The Journal of Clinical Endocrinology \& Metabolism, 87, 489-499. https://doi.org/10.1210/jcem.87.2.8182

[4] Canaris, G.J., et al. (2000) The Colorado Thyroid Disease Prevalence Study. Archives of Internal Medicine, 160, 526-534. https://doi.org/10.1001/archinte.160.4.526

[5] Society, A.C. and Society, A.C. (2018) American Cancer Society: Cancer Facts and Figures 2018. A.C. Society, Atlanta.

[6] Howlader, N.A., Krapcho, M., et al. (2017) SEER Cancer Statistics Review, 1975-2014, Based on November 2016 SEER Data Submission, Posted to the SEER Web Site. N.C. Institute, Bethesda.

[7] Henry, J.F. (2003) Applied Embryology of the Thyroid and Parathyroid Glands. In: Randolph, G., Ed., Surgery of the Thyroid and Parathyroid Glands, Saunders, Philadelphia.

[8] Skandalakis, J.E. (2004) Neck: Thyroid Gland. In: Skandalakis, J.E., Ed., Surgical Anatomy. The Embryologic and Anatomic Basis of Modern Surgery, Vol. 1, 14th Edition, Paschalidis Medical Publications, Athens.

[9] Larsen, W.J. (2001) Human Embryology. 3th Edition, Churchill Livingstone, Philadelphia, 372-374.

[10] Fancy, T., Gallagher, D. and Hornig, J.D. (2010) Surgical Anatomy of the Thyroid and Parathyroid Glands. Otolaryngologic Clinics of North America, 43, 221-227. https://doi.org/10.1016/j.otc.2010.01.001

[11] Mario De Felice, R.D.L. (2009) Thyroid Development. In: Fredric, M., Wondisford, E. and Radovick, S., Eds., Thyroid Disease, Elsevier, Philadelphia, 11. https://doi.org/10.1016/B978-1-4160-4745-2.00002-X

[12] Randolph, G.W. (2013) The Thyroid Gland. In: Randolph, G.W., Ed., Surgery of the Thyroid and Parathyroid Glands, Vol. 1, Elsevier Sanders, Philadelphia, 2nd Edition, 702. https://doi.org/10.1007/BF00284951

[13] Pearse, A.G. and Polak, J.M. (1971) Cytochemical Evidence for the Neural Crest Origin of Mammalian Ultimobranchial C Cells. Histochemie, 27, 96-102.

[14] Wolfe, H.J., et al. (1975) Distribution of Calcitonin-Containing Cells in the Normal Neonatal Human Thyroid Gland: A Correlation of Morphology with Peptide Content. The Journal of Clinical Endocrinology \& Metabolism, 41, 1076-1081. https://doi.org/10.1210/jcem-41-6-1076

[15] Gauger, P.G., et al. (2001) Incidence and Importance of the Tubercle of Zuckerkandl in Thyroid Surgery. European Journal of Surgery, 167, 249-254. https://doi.org/10.1080/110241501300091363

[16] Pelizzo, M.R., Toniato, A. and Gemo, G. (1998) Zuckerkandl's Tuberculum: An Arrow Pointing to the Recurrent Laryngeal Nerve (Constant Anatomical Landmark). Journal of the American College of Surgeons, 187, 333-336. https://doi.org/10.1016/S1072-7515(98)00160-4

[17] Welbourn, R.B. (1977) Current Status of the Apudomas. Annals of Surgery, 185, 1-12. https://doi.org/10.1097/00000658-197701000-00001

[18] Cummings, C.W. (1998) Thyroid Anatomy. In: Cummings, C.W., Head and Neck Surgery, 3rd Edition, Mosby, St. Louis.

[19] Williams, P.L. and Bannister, L.H. (1995) Thyroid Gland. In: Gray’s Anatomy, 38th Edition, Churchill Livingstone, New York.

[20] Das, S.S., Mishra, S. and Kaul, J.M. (2017) Development of Parafollicular Cells and Their Relationship with Developing Thyroid Follicles in Human Foetuses. Journal 
of Clinical and Diagnostic Research, 11, AC01-AC04.

[21] Carvalheira, A.F. and Pearse, A.G. (1967) The Cytology and Cytochemistry of the "C" Cells in the Thyroid Gland of the Pig. Journal of the Royal Microscopical Society, 86, 203-209. https://doi.org/10.1111/j.1365-2818.1967.tb00583.x

[22] Foster, R.S., Spivak, H. and Smith, C.D. (1999) Adrenals. In: Wood, W.C., Staley, C. and Skandalakis, J.E., Eds., Anatomic Basis of Tumor Surgery, Quality Medical Publishing, St. Louis.

[23] Mastin, E.V. (1922) The Blood Supply of the Thyroid Gland and Its Surgical Significance. Master's Thesis, University of Minnesota, Minneapolis, 36.

[24] Nobori, M., et al. (1994) Blood Supply of the Parathyroid Gland from the Superior Thyroid Artery. Surgery, 115, 417-423.

[25] Potenza, A.S., Araujo Filho, V.J.F. and Cernea, C.R. (2017) Injury of the External Branch of the Superior Laryngeal Nerve in Thyroid Surgery. Gland Surgery, 6, 552-562. https://doi.org/10.21037/gs.2017.06.15

[26] Hunt, P.S., Poole, M. and Reeve, T.S. (1968) A Reappraisal of the Surgical Anatomy of the Thyroid and Parathyroid Glands. British Journal of Surgery, 55, 63-66. https://doi.org/10.1002/bjs.1800550119

[27] Allan, F.D. (1952) An Accessory or Superficial Inferior Thyroid Artery in a Full Term Infant. The Anatomical Record, 112, 539-542. https://doi.org/10.1002/ar.1091120306

[28] Reed, A.F. (1943) Relations of the Inferior Laryngeal Nerve to Inferior Thyroid Artery. The Anatomical Record, 85, 17-23. https://doi.org/10.1002/ar.1090850103

[29] Polednak, A.P. (2017) Relationship of the Recurrent Laryngeal Nerve to the Inferior Thyroid Artery: A Comparison of Findings from Two Systematic Reviews. Clinical Anatomy, 30, 318-321. https://doi.org/10.1002/ca.22851

[30] Shindo, M.L., Wu, J.C. and Park, E.E. (2005) Surgical Anatomy of the Recurrent Laryngeal Nerve Revisited. Otolaryngology_Head and Neck Surgery, 133, 514-519. https://doi.org/10.1016/j.otohns.2005.07.010

[31] Hollinshead, W.H. (1982) Anatomy for Surgeons. Vol. 1, 3rd Edition, Lippincott Williams and Wilkins, Philadelphia.

[32] Mahorner, H.R., Schotthauer, C.F., et al. (1927) Observations on the Lymphatic Connections of the Thyroid Gland in Man. The Anatomical Record, 36, 341-348. https://doi.org/10.1002/ar.1090360407

[33] Randolph, G.W. (2013) Surgery Anatomy and Monitoring of the Recurrent Laryngeal Nerve. In: Surgery of the Thyroid and Parathyroid Glands, Vol. 1, 2nd Edition, Elsevier Saunders, Philadelphia, 736.

[34] Kaplan, E.L., et al. (2009) History of the Recurrent Laryngeal Nerve: From Galen to Lahey. World Journal of Surgery, 33, 386-393. https://doi.org/10.1007/s00268-008-9798-Z

[35] Uen, Y.H., et al. (2006) Surgical Anatomy of the Recurrent Laryngeal Nerves and Its Clinical Applications in Chinese Adults. Surgery Today, 36, 312-315. https://doi.org/10.1007/s00595-005-3151-Z

[36] Monnier, P. (2011) Applied Surgical Anatomy of the Larynx and Trachea. In: Monnier, P., Ed., Pediatric Airway Surgery: Management of Laryngeotracheal Stenosis in Infants and Children, Springer-Verlag, Berlin Heidelberg, 7-29.

[37] Wu, B.L., et al. (1994) The Human Communicating Nerve. An Extension of the External Superior Laryngeal Nerve That Innervates the Vocal Cord. Archives of Oto- 
laryngology_Head \& Neck Surgery, 120, 1321-1328.

https://doi.org/10.1001/archotol.1994.01880360019004

[38] Hodnett, B.L., et al. (2015) Intraoperative Identification of the Human Communicating Nerve during Thyroidectomy. Journal of Surgical Case Reports, 2015, rjv154. https://doi.org/10.1093/jscr/rjv154

[39] Sanudo, J.R., et al. (1999) An Anatomical Study of Anastomoses between the Laryngeal Nerves. Laryngoscope, 109, 983-987. https://doi.org/10.1097/00005537-199906000-00026

[40] Schweizer, V. and Dorfl, J. (1997) The Anatomy of the Inferior Laryngeal Nerve. Clinical Otolaryngology and Allied Sciences, 22, 362-369. https://doi.org/10.1046/j.1365-2273.1997.00028.x

[41] Ardito, G., et al. (2004) Revisited Anatomy of the Recurrent Laryngeal Nerves. The American Journal of Surgery, 187, 249-253. https://doi.org/10.1016/j.amjsurg.2003.11.001

[42] Sunderland, S. and Swaney, W.E. (1952) The Intraneural Topography of the Recurrent Laryngeal Nerve in Man. The Anatomical Record, 114, 411-426. https://doi.org/10.1002/ar.1091140303

[43] Maranillo, E., et al. (2003) Variability of the Nerve Supply Patterns of the Human Posterior Cricoarytenoid Muscle. Laryngoscope, 113, 602-606. https://doi.org/10.1097/00005537-200304000-00004

[44] Steinberg, J.L., et al. (1986) Anatomy of the Recurrent Laryngeal Nerve: A Re-Description. The Journal of Laryngology \& Otology, 100, 919-927. https://doi.org/10.1017/S0022215100100325

[45] Lahey, F.H. and Hoover, W.B. (1938) Injuries to the Recurrent Laryngeal Nerve in Thyroid Operations: Their Management and Avoidance. Annals of Surgery, 108, 545-562. https://doi.org/10.1097/00000658-193810000-00006

[46] Asgharpour, E., et al. (2012) Recurrent Laryngeal Nerve Landmarks Revisited. Head Neck, 34, 1240-1246. https://doi.org/10.1002/hed.21882

[47] Kaisha, W., Wobenjo, A. and Saidi, H. (2011) Topography of the Recurrent Laryngeal Nerve in Relation to the Thyroid Artery, Zuckerkandl Tubercle, and Berry Ligament in Kenyans. Clinical Anatomy, 24, 853-857. https://doi.org/10.1002/ca.21192

[48] Gurleyik, E. and Gurleyik, G. (2012) Incidence and Surgical Importance of Zuckerkandl's Tubercle of the Thyroid and Its Relations with Recurrent Laryngeal Nerve. ISRN Surgery, 2012, Article ID: 450589.

[49] Dedo, H.H. (1970) The Paralyzed Larynx: An Electromyographic Study in Dogs and Humans. Laryngoscope, 80, 1455-1517. https://doi.org/10.1288/00005537-197010000-00001

[50] Droulias, C., et al. (1976) The Superior Laryngeal Nerve. The American Surgeon, 42, 635-638.

[51] Paraskevas, G.K., et al. (2012) Topographic Anatomy of the Internal Laryngeal Nerve: Surgical Considerations. Head Neck, 34, 534-540. https://doi.org/10.1002/hed.21769

[52] Gray, H. (2008) Neck. In: Standring, S., Ed., Grays Anatomy: The Anatomical Basis of Clinical Practice, Vol. 1, 40th Edition, Churchill Livingstone, New York, 1576.

[53] Horiuchi, M. and Sasaki, C.T. (1978) Cricothyroid Muscle in Respiration. Annals of Otology, Rhinology \& Laryngology, 87, 386-391.

https://doi.org/10.1177/000348947808700318 
[54] Cernea, C.R., et al. (1992) Surgical Anatomy of the External Branch of the Superior Laryngeal Nerve. Head Neck, 14, 380-383. https://doi.org/10.1002/hed.2880140507

[55] Pagedar, N.A. and Freeman, J.L. (2009) Identification of the External Branch of the Superior Laryngeal Nerve during Thyroidectomy. Archives of Otolaryngology-Head \& Neck Surgery, 135, 360-362. https://doi.org/10.1001/archoto.2009.9

[56] Portulano, C., Paroder-Belenitsky, M. and Carrasco, N. (2014) The $\mathrm{Na}^{+} / \mathrm{I}^{-}$Symporter (NIS): Mechanism and Medical Impact. Endocrine Reviews, 35, 106-149. https://doi.org/10.1210/er.2012-1036

[57] Dunn, J.T. and Dunn, A.D. (2001) Update on Intrathyroidal Iodine Metabolism. Thyroid, 11, 407-414. https://doi.org/10.1089/105072501300176363

[58] National Institutes of Health (2016) Iodine Fact Sheet for Consumers.

[59] Leung, A.M. and Braverman, L.E. (2012) Iodine-Induced Thyroid Dysfunction. Current Opinion in Endocrinology, Diabetes and Obesity, 19, 414-419. https://doi.org/10.1097/MED.0b013e3283565bb2

[60] Kopp, P. (2005) Thyroid Hormone Synthesis. In: Braverman, L.E. and Utiger, R., Eds., Werner \& Ingbar's the Thyroid: A Fundamental and Clinical Text, Lippincott Williams \& Wilkins, Philadelphia.

[61] Dai, G., Levy, O. and Carrasco, N. (1996) Cloning and Characterization of the Thyroid Iodide Transporter. Nature, 379, 458-460. https://doi.org/10.1038/379458a0

[62] Carrasco, N.T. (2005) Hyroid Iodine Transport. In: Braverman, L.E. and Utiger, R., Eds., Werner \& Ingbar's the Thyroid: A Fundamental and Clinical Text, Lippincott Williams \& Wilkins, Philadelphia.

[63] Roti, E. and Uberti, E.D. (2001) Iodine Excess and Hyperthyroidism. Thyroid, 11, 493-500. https://doi.org/10.1089/105072501300176453

[64] Colin, I.M., et al. (2013) Recent Insights into the Cell Biology of Thyroid Angiofollicular Units. Endocrine Reviews, 34, 209-238. https://doi.org/10.1210/er.2012-1015

[65] Fong, P. (2011) Thyroid Iodide Efflux: A Team Effort? The Journal of Physiology, 589, 5929-5939. https://doi.org/10.1113/jphysiol.2011.218594

[66] Arvan, P. and Di Jeso, B. (2005) Thyroglobulin Structure, Function, and Biosynthesis. In: Braverman, L.E. and Utiger, R., Eds., Werner \& Ingbar's the Thyroid: $A$ Fundamental and Clinical Text, Lippincott Williams \& Wilkins, Philadelphia, 77-95.

[67] Yoshihara, A., et al. (2012) Regulation of Dual Oxidase Expression and $\mathrm{H}_{2} \mathrm{O}_{2}$ Production by Thyroglobulin. Thyroid, 22, 1054-1062.

https://doi.org/10.1089/thy.2012.0003

[68] Belkadi, A., et al. (2012) Phylogenetic Analysis of the Human Thyroglobulin Regions. Thyroid Research, 5, 3. https://doi.org/10.1186/1756-6614-5-3

[69] Di Jeso, B., et al. (2014) Transient Covalent Interactions of Newly Synthesized Thyroglobulin with Oxidoreductases of the Endoplasmic Reticulum. The Journal of Biological Chemistry, 289, 11488-11496. https://doi.org/10.1074/jbc.M113.520767

[70] Xiao, S., et al. (1996) Selectivity in Tyrosyl Iodination Sites in Human Thyroglobulin. Archives of Biochemistry and Biophysics, 334, 284-294. https://doi.org/10.1006/abbi.1996.0457

[71] Marino, M. and McCluskey, R.T. (2000) Role of Thyroglobulin Endocytic Pathways in the Control of Thyroid Hormone Release. American Journal of Physiology-Cell Physiology, 279, C1295-C1306. https://doi.org/10.1152/ajpcell.2000.279.5.C1295

[72] Schneider, P.B. (1964) Thyroidal Iodine Heterogeneity: "Last Come, First Served" 
System of Iodine Turnover. Endocrinology, 74, 973-980.

https://doi.org/10.1210/endo-74-6-973

[73] Bernier-Valentin, F., et al. (1990) Coated Vesicles from Thyroid Cells Carry Iodinated Thyroglobulin Molecules. First Indication for an Internalization of the Thyroid Prohormone via a Mechanism of Receptor-Mediated Endocytosis. The Journal of Biological Chemistry, 265, 17373-17380.

[74] Botta, R., et al. (2011) Binding, Uptake, and Degradation of Internalized Thyroglobulin in Cultured Thyroid and Non-Thyroid Cells. Journal of Endocrinological Investigation, 34, 515-520.

[75] Rousset, B., et al. (1989) Thyroid Hormone Residues Are Released from Thyroglobulin with Only Limited Alteration of the Thyroglobulin Structure. The Journal of Biological Chemistry, 264, 12620-12626.

[76] Gnidehou, S., et al. (2004) Iodotyrosine Dehalogenase 1 (DEHAL1) Is a Transmembrane Protein Involved in the Recycling of Iodide Close to the Thyroglobulin Iodination Site. The FASEB Journal, 18, 1574-1576. https://doi.org/10.1096/fj.04-2023fje

[77] Gnidehou, S., et al. (2006) Cloning and Characterization of a Novel Isoform of Iodotyrosine Dehalogenase 1 (DEHAL1) DEHAL1C from Human Thyroid: Comparisons with DEHAL1 and DEHAL1B. Thyroid, 16, 715-724. https://doi.org/10.1089/thy.2006.16.715

[78] Dunn, A.D., Crutchfield, H.E. and Dunn, J.T. (1991) Thyroglobulin Processing by Thyroidal Proteases. Major Sites of Cleavage by Cathepsins B, D, and L. The Journal of Biological Chemistry, 266, 20198-20204.

[79] Dunn, A.D., Myers, H.E. and Dunn, J.T. (1996) The Combined Action of Two Thyroidal Proteases Releases T4 from the Dominant Hormone-Forming Site of Thyroglobulin. Endocrinology, 137, 3279-3285. https://doi.org/10.1210/endo.137.8.8754751

[80] Di Cosmo, C., et al. (2010) Mice Deficient in MCT8 Reveal a Mechanism Regulating Thyroid Hormone Secretion. Journal of Clinical Investigation, 120, 3377-3388. https://doi.org/10.1172/JCI42113

[81] Friesema, E.C., et al. (2006) Thyroid Hormone Transport by the Human Monocarboxylate Transporter 8 and Its Rate-Limiting Role in Intracellular Metabolism. Molecular Endocrinology, 20, 2761-2772. https://doi.org/10.1210/me.2005-0256

[82] Stathatos, N. (2012) Thyroid Physiology. Medical Clinics of North America, 96, 165-173. https://doi.org/10.1016/j.mcna.2012.01.007

[83] Bartalena, L. and Robbins, J. (1993) Thyroid Hormone Transport Proteins. Clinics in Laboratory Medicine, 13, 583-598.

[84] Benvenga, S. (2005) Thyroid Hormone Transport Proteins and the Physiology of Hormone Binding. In: Braverman, L.E. and Utiger, R., Eds., Werner \& Ingbar's the Thyroid: A Fundamental and Clinical Text, Lippincott Williams \& Wilkins, Philadelphia.

[85] Schussler, G.C. (2000) The Thyroxine-Binding Proteins. Thyroid, 10, 141-149. https://doi.org/10.1089/thy.2000.10.141

[86] Fu, J. and Dumitrescu, A.M. (2014) Inherited Defects in Thyroid Hormone Cell-Membrane Transport and Metabolism. Best Practice \& Research: Clinical Endocrinology \& Metabolism, 28, 189-201. https://doi.org/10.1016/j.beem.2013.05.014

[87] Dentice, M., et al. (2013) The Deiodinases and the Control of Intracellular Thyroid Hormone Signaling during Cellular Differentiation. Biochimica et Biophysica Acta, 
1830, 3937-3945. https://doi.org/10.1016/j.bbagen.2012.05.007

[88] Maia, A.L., et al. (2011) Deiodinases: The Balance of Thyroid Hormone: Type 1 Iodothyronine Deiodinase in Human Physiology and Disease. Journal of Endocrinology, 209, 283-297. https://doi.org/10.1530/JOE-10-0481

[89] Cheng, S.Y., Leonard, J.L. and Davis, P.J. (2010) Molecular Aspects of Thyroid Hormone Actions. Endocrine Reviews, 31, 139-170. https://doi.org/10.1210/er.2009-0007

[90] Brent, G.A. (2012) Mechanisms of Thyroid Hormone Action. Journal of Clinical Investigation, 122, 3035-3043. https://doi.org/10.1172/JCI60047

[91] Hollenberg, A.N. (2008) The Role of the Thyrotropin-Releasing Hormone (TRH) Neuron as a Metabolic Sensor. Thyroid, 18, 131-139. https://doi.org/10.1089/thy.2007.0251

[92] Sellitti, D.F. and Suzuki, K. (2014) Intrinsic Regulation of Thyroid Function by Thyroglobulin. Thyroid, 24, 625-638. https://doi.org/10.1089/thy.2013.0344

[93] Zoeller, R.T., Tan, S.W. and Tyl, R.W. (2007) General Background on the Hypothalamic-Pituitary-Thyroid (HPT) Axis. Critical Reviews in Toxicology, 37, 11-53. https://doi.org/10.1080/10408440601123446

[94] Markou, K., et al. (2001) Iodine-Induced Hypothyroidism. Thyroid, 11, 501-510. https://doi.org/10.1089/105072501300176462

[95] Ross, M.H. and Pawlina, W. (1985) Endocrine Organs: Thyroid Gland. In: Histology: A Text and Atlas with Correlated Cell and Molecular Histology, Vol. 1, 6th Edition, Wolters Kluwer/Lippincott Williams and Wilkins, New York. 